OPEN ACCESS

Edited by:

Song Yang,

Sun Yat-sen University, China

Reviewed by:

Jia Liang,

Nanjing University of Information Science and Technology, China

Xue Xu,

Guizhou University, China

*Correspondence: Wenjing Shi

shiwenjing_005@163.com

Ziniu Xiao

xiaozn@lasg.iap.ac.cn

Wei Cheng

chengw@mail.iap.ac.cn

Specialty section:

This article was submitted to

Atmospheric Science,

a section of the journal

Frontiers in Earth Science

Received: 07 September 2021

Accepted: 29 October 2021

Published: 06 December 2021

Citation:

Shi W, Wang Q, Xiao Z, Cheng W and

Duan W (2021) Modulation of Atlantic

Multidecadal Oscillation on the

Interdecadal Variation of South Asian

High and Somali Jet in Summer.

Front. Earth Sci. 9:772202.

doi: 10.3389/feart.2021.772202

\section{Modulation of Atlantic Multidecadal Oscillation on the Interdecadal Variation of South Asian High and Somali Jet in Summer}

\author{
Wenjing Shi ${ }^{1,2,3 *}$, Qingzhe Wang ${ }^{1}$, Ziniu Xiao ${ }^{2 *}$, Wei Cheng $^{3,4 *}$ and Wei Duan ${ }^{5}$ \\ ${ }^{1}$ CSSC Marine Technology Co. Ltd., Beijing, China, ${ }^{2}$ State Key Laboratory of Numerical Modeling for Atmospheric Sciences and \\ Geophysical Fluid Dynamics (LASG), Institute of Atmospheric Physics, Chinese Academy of Sciences, Beijing, China, ${ }^{3}$ State Key

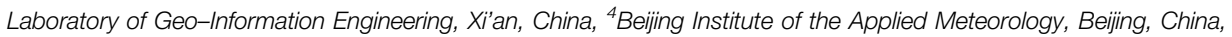 \\ ${ }^{5}$ Meteorological Science Institute of Yunnan Province, Kunming, China
}

As two important components of the Asian summer monsoon system, the intensities of South Asian High (SAH) and Somali jet (SMJ) in summer exhibit both interannual and decadal variabilities. On the interdecadal timescale, the temporal evolution of the SAH intensity is in phase with that of the SMJ intensity. By comparison, we find that both of them evolve synchronously with the Atlantic Multidecadal Oscillation (AMO), with AMO cold/ warm phases corresponding to the weakening/strengthening of SAH and SMJ. Further diagnoses indicate that the interdecadal variabilities of the SAH and SMJ intensities in summer may be modulated by the AMO phase. Mechanistically, this modulation appears to be achieved via an interdecadal Silk Road pattern (SRP)-like wave train along the Asian westerly jet and Matsuno-Gill tropical atmospheric response. The cold SST anomaly over extratropical North Atlantic related to the AMO firstly induces an anomalous high over Western Europe and produces a well-organized wave train between $30^{\circ} \mathrm{N}$ and $60^{\circ} \mathrm{N}$. The anomalous Iranian Plateau low along with the wave train path leads to a weakened $\mathrm{SAH}$. Besides, the AMO-related cold SST anomalies over tropical North Atlantic cool the tropical tropospheric atmosphere through the moist adjustment process and produce a Matsuno-Gill-like atmospheric response covering the tropical Indian Ocean. Due to the Matsuno-Gill response, subsidence motion anomalies over the central tropical Indian Ocean corresponding to a result in increased lower-level divergence and upper-level convergence are excited over the tropical Indian Ocean. Finally, the tropical Indian Ocean divergence in the lower troposphere leads to the weakened summer SMJ, and the tropical Indian Ocean convergence in the upper troposphere results in the decrease and northward displacement of SAH in summer.

Keywords: South Asian High, somali jet, Atlantic multidecadal oscillation, interdecadal variability, silk road pattern, extratropical and tropical North Atlantic SSTs 


\section{INTRODUCTION}

The Atlantic Multidecadal Oscillation (AMO) is a prominent basin-scale mode of multidecadal variability in North Atlantic sea surface temperatures (SSTs). Bjerknes (1964) first found the consistent variations of SSTs and sea level pressures (SLPs) in $30^{\circ}-50^{\circ} \mathrm{N}$ of the North Atlantic during $1920-1960$, with a gradually warming trend. Subsequently, Folland and Parker (1990) revealed that the North Atlantic SSTs gradually entered into a cooling stage from 1960 to 1980. After 1990, the North Atlantic SSTs were warming up again (Delworth and Mann, 2000; Kerr, 2000). Kerr (2000) formally defined this multidecadal variability in North Atlantic SSTs as the AMO. The AMO showed two leading periodicities of about $60-80$ and $10-30$ years with different regimes (Lin et al., 2019), which have an important impact on global climate, regional climate, and even El Niño-Southern Oscillation (ENSO) (Knight et al., 2006; Li and Bates, 2007; Feng and Hu, 2008; Li et al., 2008; Luo et al., 2011).

The AMO influence on the Indian summer monsoon (ISM) has been investigated by several recent studies based on observations and models. The positive phase of the AMO could induce increased summer rainfall in central and southern Indian, intensified ISM, and late withdrawal of the ISM (Goswami et al., 2006; Sutton and Hodson, 2007; Li et al., 2008; Wang et al., 2009). Despite an overall consistency of the AMO influence on the ISM in previous studies, there are still some disputes about the magnitude of the forcing and the responsible mechanism. Based on observations, Goswami et al. (2006) proposed that a positive-phase AMO induces atmospheric responses like the summer North Atlantic Oscillation (NAO) pattern, leading to warming over the Eurasian continent and intensifying thermal contrast between the Indian subcontinent and the tropical Indian Ocean and consequently stronger ISM. Feng and $\mathrm{Hu}$ (2008) suggested a different mechanism in which the AMO exerts its impact by changing surface thermal status over the Tibetan Plateau rather than the summer NAO. Through Atmospheric General Circulation Model (AGCM), Li et al. (2008) and Wang et al. (2009) also suggested that the AMO influences the India Summer Rainfall (ISR) via an increased meridional gradient of the tropospheric temperatures and intensification of the monsoonal low-level jet, but no significant NAO-like responses. Luo et al. (2011) viewed that the AMO influence on ISR is achieved through a propagating Rossby wave train from the North Atlantic across South Asia, which leads to enhanced South Asian High (SAH) and consequently a strengthening of the ISM.

In addition to the impact on the ISM, the AMO also has a certain modulation effect on summer precipitation in East Asia. The AMO warm phase is conducive to the enhancement of the East Asian summer monsoon (EASM) and the increase of precipitation in the Yangtze River Basin (Lu et al., 2006; Li et al., 2008). The warm AMO-related North Atlantic SSTs are favorable for the earlier onset of Meiyu, and the cold SSTs over North Atlantic in preceding winter and spring are related to the later onset of Meiyu (Xu et al., 2001). Wang and Li (2019) also pointed out that the turning of summer eastern China precipitation in the early 1990 s is related to the AMO with its impact mainly concentrated in low-latitude regions.
The circumglobal teleconnection (CGT) pattern is a leading circulation mode over the Northern Hemisphere $(\mathrm{NH})$ during boreal summer, which is propagating around the hemisphere along the subtropical upper-tropospheric westerly jet (Ding and Wang, 2005). The wave train propagating over the Eurasian continent (Lu et al., 2002) or the Silk Road pattern (SRP) (Enomoto, 2004) is considered to be a portion of the CGT. Recent studies found that the AMO has a considerable impact on this teleconnection pattern. Using five AGCMs driven by specified AMO-related SST anomalies (SSTAs) in the North Atlantic, Lin et al. (2016) verified that the interdecadal component of the CGT (ID-CGT) should be excited, at least partially, by the AMO-related SSTAs, and ID-CGT plays a role in linking the AMO and $\mathrm{NH}$ summer land surface air temperature (SAT) perturbations on the interdecadal timescale. Based on the 20CR data, Wu et al. (2016) also indicated that, during boreal summer, AMO-related SSTAs are associated with a wave trainlike teleconnection pattern located along the $\mathrm{NH}$ westerly jet.

As two of the most important components of the Asian summer monsoon system, SAH and Somali jet (SMJ) have influence on the weather and climate in the Asian regions (e.g., Krishnamurti and Bhalme, 1976; Cadet and Desbois, 1981; Halpern and Woiceshyn, 2001; Huang and Qian, 2004; Lei and Yang, 2008; Watanabe and Yamazaki, 2014; Wei et al., 2014). The SAH is a large-scale anticyclone circulation system over the Tibetan Plateau and its adjacent regions in summer. In addition to the polar vortex, the $\mathrm{SAH}$ is suggested to be the strongest and most stable atmospheric circulation system in the upper troposphere $(100 \mathrm{hPa})$ of $\mathrm{NH}$ (Mason and Anderson, 1963; He et al., 2006; Liu et al., 2009). On the other hand, the SMJ is a low-level cross-equatorial flow (CEF) at the strategic fulcrum of the Indian Ocean, characterized by southeasterly trade winds in the Southern Hemisphere, a strong and narrow CEF off the coast of Somalia, and southwesterly winds over the Arabian Sea (Simpson, 1921; Joseph and Raman, 1966; Findlater, 1969; Krishnamurti and Bhalme, 1976; Qian et al., 1987; Chakraborty et al., 2009; Pu and Cook, 2010). This low-level current is most prominent in summer and has its maximum wind speed center at approximately $925 \mathrm{hPa}(\mathrm{Pu}$ and Cook, 2010; Xiao et al., 2015). These two important atmospheric circulation systems of the $\mathrm{NH}$ in summer change not only interannually but also interdecadally (Zhang et al., 2000; Shi et al., 2007; Boos and Emanuel, 2009; Pu and Cook, 2010; Zhu, 2012; Yang et al., 2013; Jia and Liu, 2020). As Shi et al. (2007) investigated, the strength of the SMJ increased, on average, by $0.25 \mathrm{~m} \mathrm{~s}^{-1}$ per decade during 1948-2004. Zhu (2012) demonstrated that the low-level $(925-\mathrm{hPa})$ Somali CEFs showed a strong upward trend, with two marked increases in strength in the late 1970s and the late 1990s. Moreover, Zhang et al. (2000) pointed out that the mutation of the SAH strength in the late 1970s is consistent with that of the Pacific SSTs. Yang et al. (2013) also suggested that the interdecadal transition of the SAH intensity occurred in the late 1970s, which was associated with the anomalies of the surface sensible heat flux in the plateau (especially in the northwest of the plateau). Actually, on the interdecadal timescale, the temporal evolution of the SAH is synchronous with that of the SMJ during 1951-2010 characterized by one-wave type. When the $\mathrm{SMJ}$ is weak (strong), the summertime SAH is also weak (strong) and 
TABLE 1 | Datasets used in this study.

\begin{tabular}{|c|c|c|c|}
\hline Dataset & Resolution & Pressure levels & Period of record \\
\hline JRA-55 reanalysis & $1.25^{\circ} \times 1.25^{\circ}$ & $37(1,000-1$ hPa $)$ & 1958-2021 \\
\hline NCEP/NCAR reanalysis & $2.5^{\circ} \times 2.5^{\circ}$ & $17(1,000-10 \mathrm{hPa})$ & 1948-2021 \\
\hline 20CRv3 reanalysis & $1^{\circ} \times 1^{\circ}$ & $28(1,000-1 \mathrm{hPa})$ & $1836-2015$ \\
\hline ERA-20c reanalysis & $1^{\circ} \times 1^{\circ}$ & $37(1,000-1 \mathrm{hPa})$ & 1900-2010 \\
\hline HadISST1.1 & $1^{\circ} \times 1^{\circ}$ & Surface & $1870-2021$ \\
\hline
\end{tabular}

Note. JRA-55, Japanese 55-year Reanalysis; NCEP/NCAR, National Centers for Environmental Prediction/National Center for Atmospheric Research; 20CRv3, Twentieth Century Reanalysis dataset, version 3; ERA-20c, European Centre for Medium-Range Weather Forecasts 20th-century reanalysis.

retreats westward (advances eastward) (Shi et al., 2017). As mentioned above, the AMO plays an important role in components of the Asian summer monsoon system, e.g., ISM, EASM, and ID-CGT. However, it remains unclear whether the $\mathrm{AMO}$, as one of the most important interdecadal atmospheric signals, has dominant modulation impact on the interdecadal variabilities of the SAH and SMJ in summer. This topic is focused on in this study. The Data and Methods section describes the data and methods used in this study. The Interdecadal Variations of the South Asian High, Somali Jet, and Atlantic Ocean Sea Surface Temperature in Summer section presents the interdecadal variation of the SAH and SMJ intensities, as well as their linkages with the AMO. The Modulation Mechanism of the Summer South Asian High and Somali jet by the Atlantic Multidecadal Oscillation on an Interdecadal Timescale section further investigates the modulation mechanism of the AMO phase-related SSTAs on the SAH and SMJ interdecadal variabilities in summer via an interdecadal SRP-like wave train along the Asian westerly jet and Matsuno-Gill-like tropical atmospheric response. The Summary section provides a summary of key findings in this study.

\section{DATA AND METHODS}

In order to satisfy the requirements of the decadal variability analyses, several long-term monthly mean atmospheric reanalysis datasets are used in this study, including the National Centers for Environmental Prediction (NCEP)/National Center for Atmospheric Research (NCAR) reanalysis dataset (Kalnay et al., 1996, https://psl.noaa.gov/data/gridded/data.ncep. reanalysis.html), the Japanese 55-year Reanalysis (JRA-55) dataset (Kobayashi et al., 2015, http://search.diasjp.net/en/ dataset/JRA55), the European Centre for Medium-Range Weather Forecasts (ECMWF) 20th-century reanalysis (ERA-20c) dataset (Poli et al., 2013, https://apps.ecmwf. int $/$ datasets $/$ data/era20c - moda/levtype $=\mathrm{pl} /$ type $=a n /$ ), and the Twentieth Century Reanalysis dataset, version 3 (20CRv3; Compo et al., 2011, https://psl.noaa.gov/data/ gridded/data.20thC_ReanV3.html). The variables include horizontal wind, geopotential height, vertical velocity, air temperature, specific humidity, and relative vorticity at pressure levels, SLP and SAT. In addition, the monthly mean SST data are obtained from the Version 1.1 Hadley Center Global Sea Ice and Sea Surface Temperature (HadISST1.1; Rayner et al., 2003) dataset that is available online from the United Kingdom Met Office (http://www.
metoffice.gov.uk/hadobs/HadISST1.1/). The resolution, pressure level, and record period of these data are given in Table 1.

The summer is defined as the average of June, July, and August (JJA). The SMJ strength index (SMJI) is defined to check the SMJ strength variation. Following Dai and Xiao (2014), the SMJI is calculated by area weighted averaging the $925-\mathrm{hPa}$ meridional wind over the region of (equator; $40^{\circ}-55^{\circ} \mathrm{E}$ ), where the $\mathrm{SMJ}$ is generally located. The intensity of the SAH (SAHI) is defined as the sum of differences between the geopotential height at each point and the characteristic one (i.e., 16,600 gpm) over the $\mathrm{SAH}$ region $\left(10^{\circ} \mathrm{S}-50^{\circ} \mathrm{N}, 30^{\circ} \mathrm{W}-180^{\circ} \mathrm{E}\right)$ following the method proposed in Zhang et al. (2002, 2005). The area of the SAH (SAHA) is computed by counting the points at which the geopotential height is equal to or greater than the characteristic height of $16,600 \mathrm{gpm}$ in the region (Zhou et al., 2006). The SRP pattern is defined as the first empirical orthogonal function (EOF) mode of the summer mean 200$\mathrm{hPa}$ meridional wind over the domain $\left(20^{\circ}-60^{\circ} \mathrm{N}, 30^{\circ}-130^{\circ} \mathrm{E}\right.$; Kosaka et al., 2009), and the SRP index is defined as the normalized first principal component accordingly. Following Ting et al. (2009), the AMO index is defined as area-averaged SSTAs in the North Atlantic $\left(0^{\circ}-60^{\circ} \mathrm{N}, 80^{\circ} \mathrm{W}-0^{\circ}\right)$ with the linear trend signal removed through regression analysis. To maintain consistency and for easy comparisons among the datasets with consideration for their different temporal coverages, the analysis periods of this study are the overlapping periods of different datasets (i.e., 1958-2010 for JRA-55, 1948-2010 for NCEP/NCAR, and 1900-2010 for 20CRv3 and ERA-20c). Since we focus on the decadal variability, the linear trend signals in all statistical analysis datasets are removed to isolate the contribution of the trends from that of natural variability (Nan et al., 2009). The interdecadal component of a variable is extracted using a 9 -year Gaussian low-pass filter. The statistical significance of composite is evaluated based on a two-tailed Student's t-test, and the effective degree of freedom $\left(\mathrm{N}_{\mathrm{dof}}\right)$ is evaluated as follows (Zhou and Zheng, 1999):

$$
\begin{aligned}
& \mathrm{N}_{\mathrm{dof}}=(N-2) \frac{f_{p}}{f_{n}} \\
& f_{n}=\frac{1}{2 \Delta}, \quad f_{p}=\frac{1}{\mathrm{~N}_{l} \Delta}-\frac{1}{\mathrm{~N}_{h} \Delta}
\end{aligned}
$$

where $\mathrm{N}$ is the sample size and $\Delta$ is the sample spacing. $\mathrm{N}_{h}$ and $\mathrm{N}_{1}$ represent the maximum and minimum sample sizes passed in the filtering process, respectively. $f_{n}$ and $f_{p}$ are the Nyquist frequency 

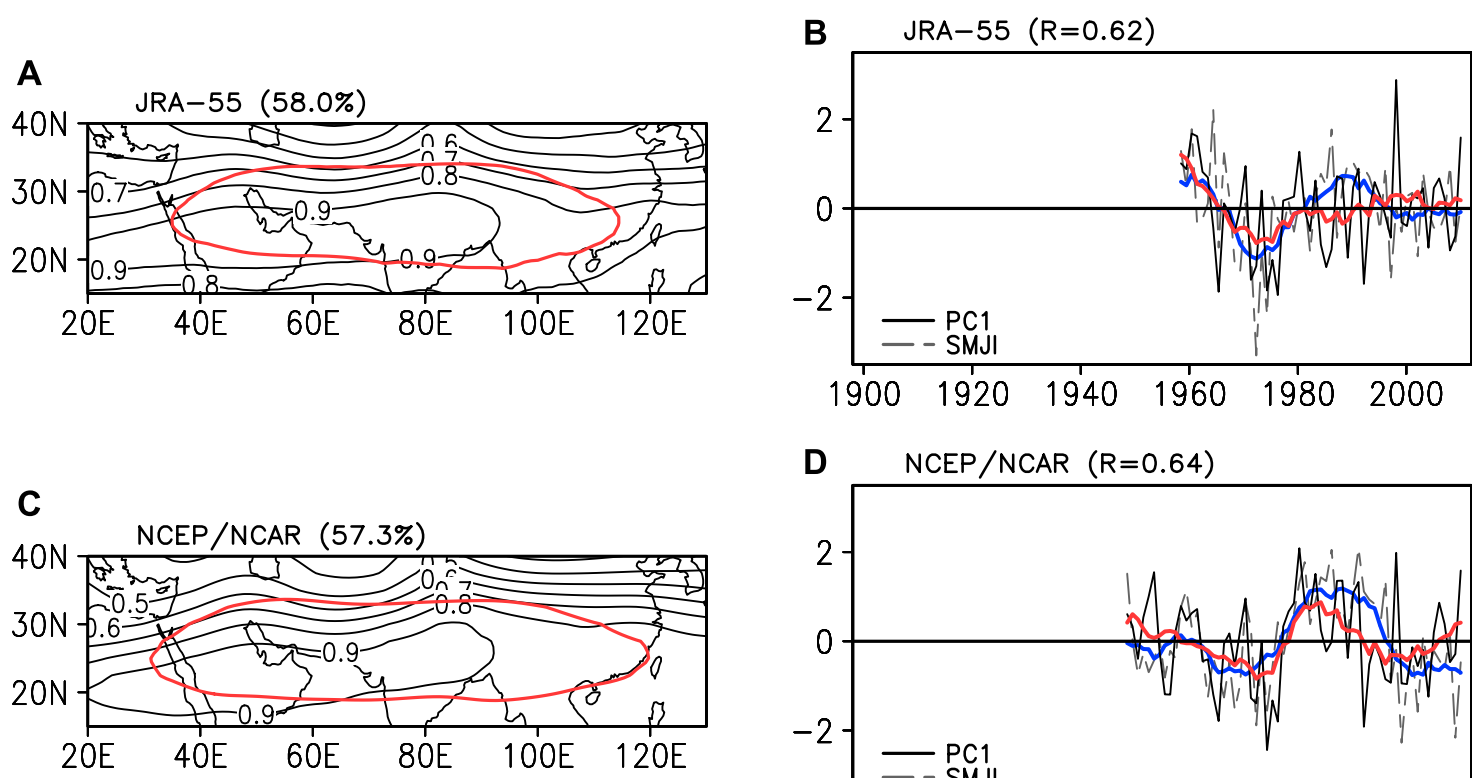

D NCEP/NCAR $(R=0.64)$
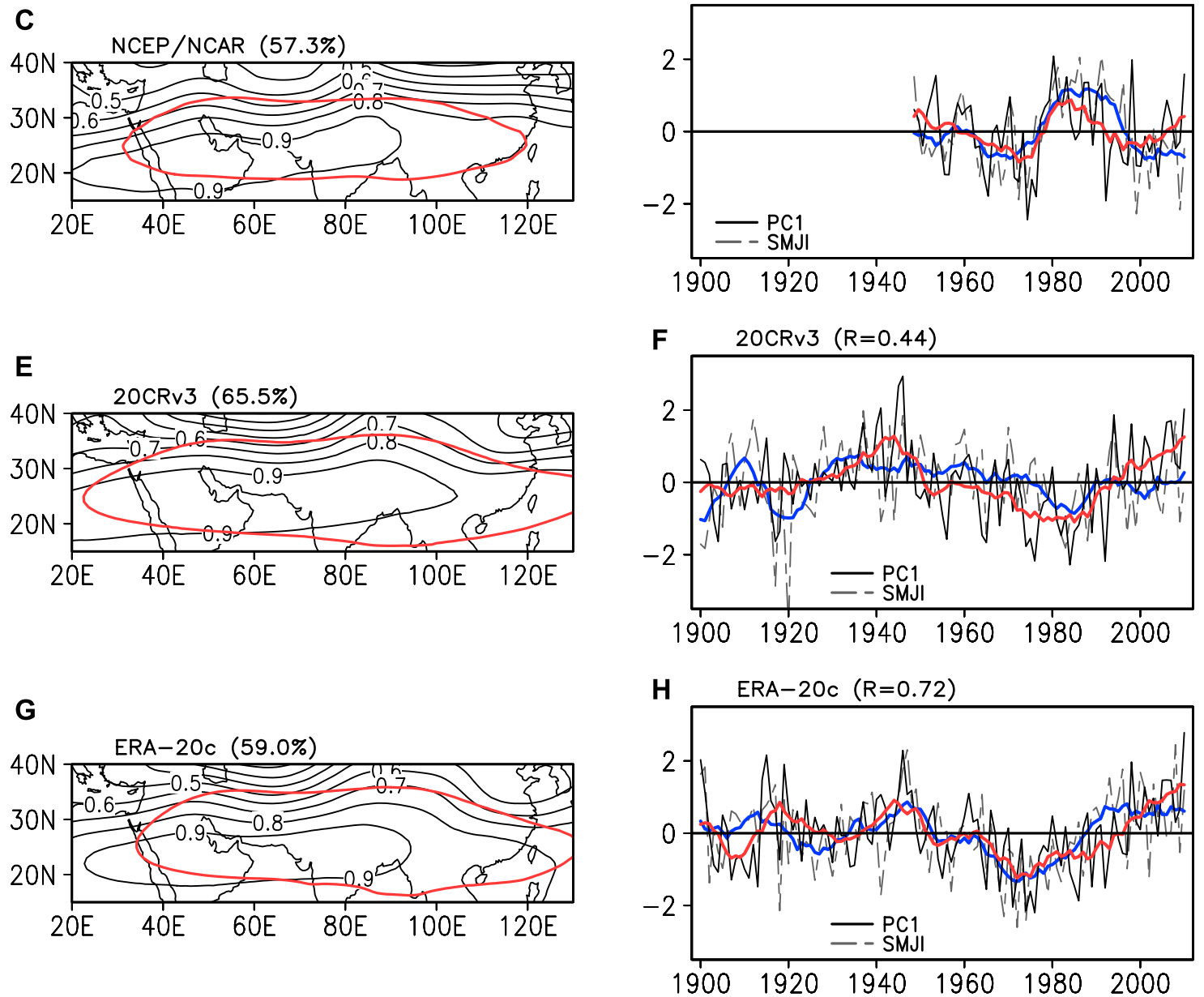

FIGURE 1 | Spatial pattern of the first EOF for the summer geopotential height anomalies (gpm) at $200 \mathrm{hPa}$ in the (A) JRA-55, (C) NCEP/NCAR, (E) 20CRv3, and (G) ERA-20c datasets. The red contour denotes climatological location of the summer SAH featured by the 12,500 gpm (for the JRA-55, NCEP/NCAR, and 20CRv3 datasets) and 12,400 gpm (for the ERA-20c dataset) contours. Contour intervals are $0.1 \mathrm{gpm}$. The normalized time series of the SMJl (gray dashed line) and the principal component time series of the first EOF (PC1; black solid line) with their 9-year running averaged components, respectively, denoted by blue and red solid lines in the (B) JRA-55, (D) NCEP/NCAR, (F) 20CRv3, and (H) ERA-20c datasets. EOF, empirical orthogonal function; JRA-55, Japanese 55-year Reanalysis; NCEP/NCAR, National Centers for Environmental Prediction/National Center for Atmospheric Research; 20CRv3, Twentieth Century Reanalysis dataset, version 3; ERA-20c, European Centre for Medium-Range Weather Forecasts 20th-century reanalysis; SAH, South Asian High; SMJI, Somali jet strength index.

and the pass bandwidth of the frequency, respectively. In this study, the wave-activity flux for stationary Rossby waves is analyzed to investigate the propagation direction of wave energy as proposed by Takaya and Nakamura (2001). Its horizontal components in pressure coordinates are as follows:

$$
\mathrm{W}=\frac{1}{2|\overline{\mathbf{u}}|}\left\{\begin{array}{l}
\bar{u}\left(\Psi_{x}^{2}-\Psi^{\prime} \Psi_{x x}^{\prime}\right)+\bar{v}\left(\Psi_{x}^{\prime} \Psi^{\prime}{ }_{y}-\Psi^{\prime} \Psi_{x y}^{\prime}\right) \\
\bar{u}\left(\Psi_{x}^{\prime}{ }_{x}^{\prime} \Psi_{y}^{\prime}-\Psi^{\prime} \Psi_{x y}^{\prime}\right)+\bar{v}\left(\Psi_{y}^{\prime^{2}}-\Psi^{\prime} \Psi^{\prime}{ }_{y y}\right)
\end{array}\right\}
$$

Here, overbars and primes denote mean states and deviations from the mean states, respectively; subscripts $x$ and $y$ represent 
TABLE 2 | Correlation coefficients between the PC1 and SAHI index in the different datasets.

\begin{tabular}{cccc} 
JRA-55 & NCEP/NCAR & 20CRv3 & ERA-20c \\
\hline 0.96 & 0.85 & 0.92 & 0.87
\end{tabular}

Note. All of the correlation coefficients exceed the $99.9 \%$ confidence level based on twotailed Student's t-test.

PC1, the first principal component of the 200-hPa geopotential height. JRA-55, Japanese 55-year Reanalysis. NCEP/NCAR, National Centers for Environmental Prediction/National Center for Atmospheric Research; 20CRv3, Twentieth Century Reanalysis dataset, version 3; ERA-20c, European Centre for Medium-Range Weather Forecasts 20th-century reanalysis.

zonal and meridional gradients; $\mathbf{u}=(u, v)$ denotes horizontal wind velocity; $\Psi$ represents eddy stream functions.

\section{INTERDECADAL VARIATIONS OF THE SOUTH ASIAN HIGH, SOMALI JET, AND ATLANTIC OCEAN SEA SURFACE TEMPERATURES IN SUMMER}

\section{Variations of the South Asian High, Somali Jet, and Atlantic Multidecadal Oscillation Indices}

We first examine the variability of the SAH, SMJ, and AMO on the interdecadal timescale using four reanalysis datasets from 1958 to 2010 for JRA-55, 1948-2010 for NCEP/NCAR, and 1900-2010 for 20CRv3 and ERA-20c. Following previous studies (Wei et al., 2014, 2015), the dominant modes of the $200-\mathrm{hPa}$ geopotential height anomalies over $\left(15^{\circ}-40^{\circ} \mathrm{N}\right.$; $20^{\circ}-130^{\circ} \mathrm{E}$ ), where the main body of the $\mathrm{SAH}$ is generally located, extracted by the EOF technique are usually used to examine the SAH variation. Figure 1 shows the first EOF (EOF1) modes and the corresponding principal component (PC1) time series of the summer 200-hPa geopotential height anomalies from four reanalysis datasets. Spatial patterns of the EOF1 show same-sign geopotential height anomalies over the considered area and seem obviously consistent in four reanalysis datasets (Figures 1A,C,E,G). The EOF1s of the JRA-55, NCEP/
NCAR, 20CRv3, and ERA-20c account for 58\%, 57.3\%, 65.6\%, and $59 \%$ of the total variances, respectively. The correlation coefficients between the PC1 and the normalized SAHI index are calculated in Table 2 for the different datasets. The two time series are highly consistent with each other in four datasets with all of the correlation coefficients exceeding 0.8. Thus, the EOF1 represents the variation of the SAH strength.

Before any analysis is performed, the consistency of the $\mathrm{SAH}$ and SMJ strength variabilities represented by the different datasets is checked by calculating the correlation coefficients of the PC1 and SMJI time series among the datasets (Table 3). Almost all of the correlation coefficients exceed the $95 \%$ confidence level based on two-tailed Student's t-test, except for the correlation coefficients of the SMJI index between the NCEP/ NCAR and 20CRv3 dataset. The SAH strength variability in the ERA-20c dataset is highly consistent with that in the JRA-55 and 20CRv3 datasets, with all the correlation coefficients on the order of 0.75 or higher during their overlapping periods. In contrast, the SMJ strength variability is less consistent among the different datasets with only the correlation coefficients between the ERA20c and JRA-55 datasets for the period of 1958-2010 exceeding 0.7. Therefore, the ERA-20c datasets during the period of $1900-2010$ is used throughout this study except where otherwise stated explicitly. As evidenced by Figures 1B,D,F,H, the remarkable interdecadal variabilities of the SAH and SMJ strength are clearly seen by PC1 and SMJI time series. Except for the 20CRv3 dataset, almost all of the correlation coefficients between the 9-year running averaged component of the PC1 and those of the SMJI in the different datasets are on the order of 0.6 , exceeding the $99 \%$ confidence level. The time series of the SMJI on the interdecadal timescale is in phase with that of the $\mathrm{PC} 1$ as shown by the 9-year running averaged component of the PC1 and SMJI. Our previous work also verified the positive correlation between SMJ strength and South Asian High on interdecadal timescale, when the SMJ strength is weak (strong), the summertime South Asian High is also weak (strong) and retreats westward (advances eastward) (Shi et al., 2017). As revealed by previous studies, the synchronous variability of the SAH and SMJ strength could be achieved via the upper-level tropical easterly jet across the Indian subcontinent (Ashfaq et al., 2009; Hu et al., 2010; Ren et al.,

TABLE 3 | Correlation coefficients of the SMJI and PC1 indexes among the different datasets for the periods 1958-2010, 1948-2010, and 1900-2010.

\begin{tabular}{|c|c|c|c|c|c|c|}
\hline \multirow[b]{2}{*}{ 1958-2010 } & \multicolumn{3}{|c|}{ SMJI index } & \multicolumn{3}{|c|}{ PC1 index } \\
\hline & NCEP/NCAR & 20CRv3 & ERA-20c & NCEP/NCAR & 20CRv3 & ERA-20c \\
\hline JRA-55 & 0.56 & 0.45 & 0.78 & 0.81 & 0.74 & 0.88 \\
\hline NCEP/NCAR & - & 0.21 & 0.36 & - & 0.48 & 0.64 \\
\hline 20CRv3 & - & - & 0.57 & - & - & 0.83 \\
\hline 1948-2010 & 20CRv3 & ERA-20c & & 20CRv3 & ERA-20c & \\
\hline NCEP/NCAR & 0.22 & 0.31 & & 0.51 & 0.65 & \\
\hline 20CRv3 & - & 0.53 & & - & 0.82 & \\
\hline 1900-2010 & ERA-20c & & & ERA-20c & & \\
\hline 20CRv3 & 0.28 & & & 0.75 & & \\
\hline
\end{tabular}

Note. PC1, the first principal component of the 200-hPa geopotential height. SMJl, Somali jet strength index; NCEP/NCAR, National Centers for Environmental Prediction/National Center for Atmospheric Research; 20CRv3, Twentieth Century Reanalysis dataset, version 3; ERA-20c, European Centre for Medium-Range Weather Forecasts 20th-century reanalysis; JRA-55, Japanese 55-year Reanalysis. 

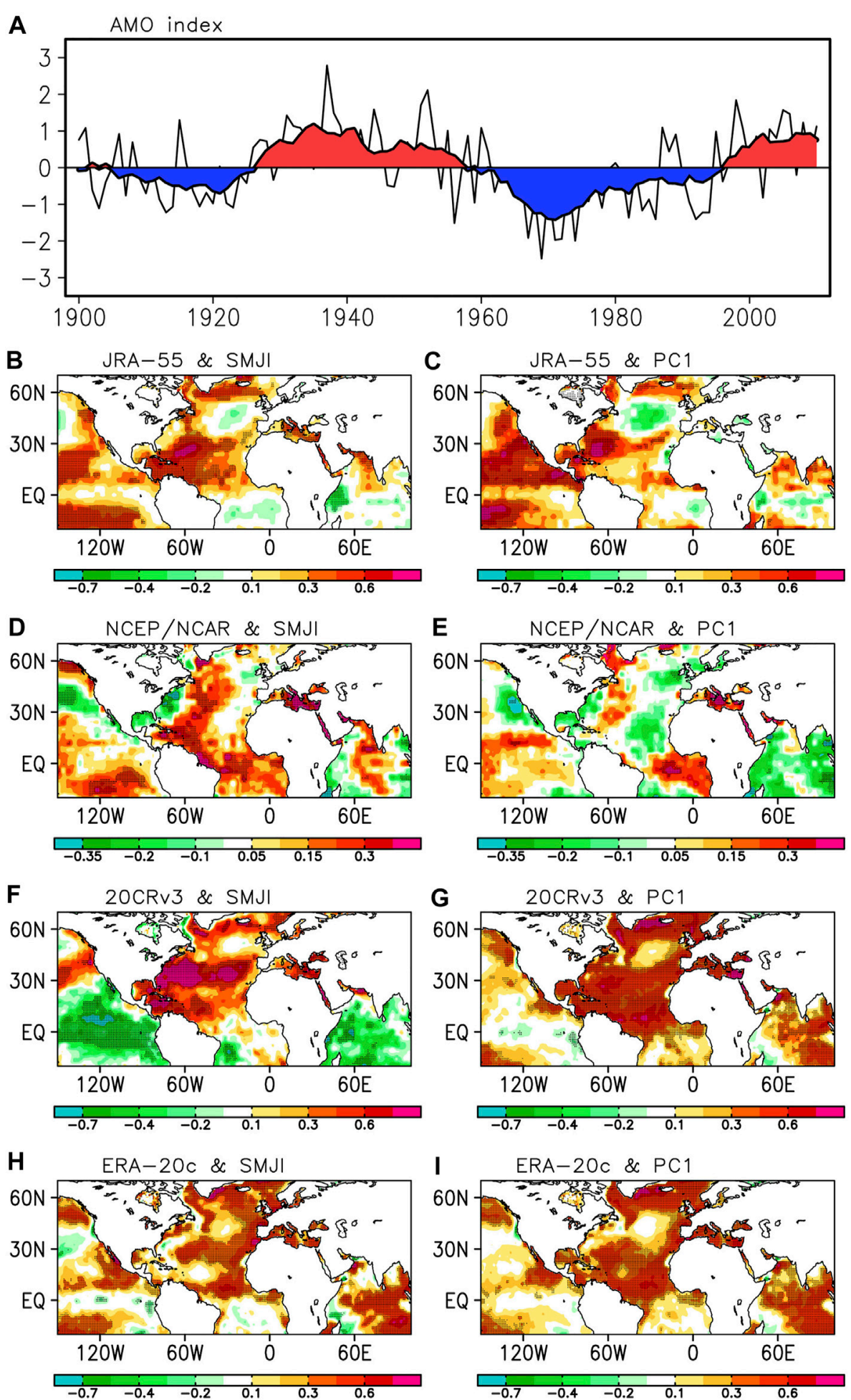

FIGURE 2 | (A) Normalized summer AMO index (black solid line) time series and its interdecadal component (thick line with filled colors) during the time period 1900-2010. Regressions of the summer SST (units: K) interdecadal component onto the interdecadal component of the summer (B,D,F,H) SMJI and (C,E,G,I) PC1 from the (B,C) JRA-55, (D,E) NCEP/NCAR, (F,G) 20CRv3, and (H,I) ERA-20c datasets. Black dots indicate the 95\% confidence levels based on two-tailed Student's t-test. AMO, Atlantic Multidecadal Oscillation; SST, sea surface temperature; SMJI, Somali jet strength index; JRA-55, Japanese 55-year Reanalysis; NCEP/NCAR, National Centers for Environmental Prediction/National Center for Atmospheric Research; 20CRv3, Twentieth Century Reanalysis dataset, version 3; ERA-20c, European Centre for Medium-Range Weather Forecasts 20th-century reanalysis. 

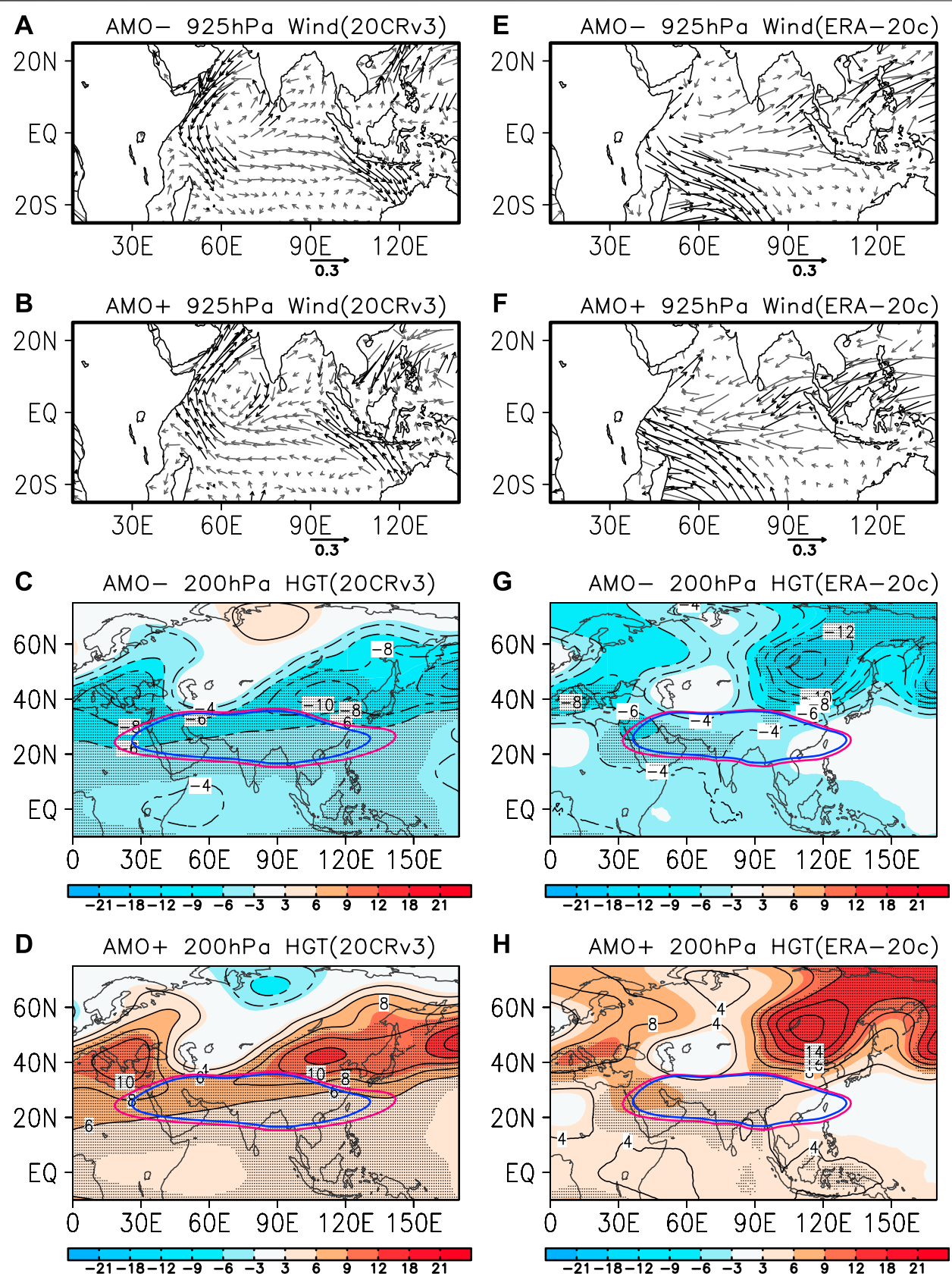

FIGURE 3 | A composite of the summer (A,B,E,F) 925-hPa wind anomalies (unit: $\mathrm{m} \mathrm{s}^{-1}$ ) and (C,D,G,H) 200-hPa geopotential height anomalies (gpm) during (A,E,C,G) AMO- and (B,F,D,H) AMO+ from the (A-D) 20CRv3 and (E-H) ERA-20c datasets. The blue and pink solid contour denotes composites of the 12,500 gpm (for the 20CRv3 dataset) or 12,400 gpm (for the ERA-20c dataset) contour at $200 \mathrm{hPa}$ during AMO- or AMO+ periods in summer. Contour intervals are $\pm 4, \pm 6, \pm 8, \pm 10$, \pm 12 , and $\pm 14 \mathrm{gpm}$ (C,D) and $\pm 4, \pm 8, \pm 10, \pm 12, \pm 14$, and $\pm 16 \mathrm{gpm}$ (G,H). Dots and black bold vectors denote values that attained the $95 \%$ significance level. AMO, Atlantic Multidecadal Oscillation; 20CRv3, Twentieth Century Reanalysis dataset, version 3; ERA-20c, European Centre for Medium-Range Weather Forecasts 20thcentury reanalysis.

2014; Shi et al., 2017). A stronger summer SAH changes the upper-level wind circulations and leads to the anomalous easterly flow over the south of the SAH location (represents a stronger upper-level tropical easterly jet). Thus, anomalous lowerlevel westerly flow over the Arabian Sea occurs via the meridional circulation of the ISM and leads to a strengthening of the SMJ.
The AMO is one of the two leading modes of the internally generated interdecadal variability of the climate system (the other is the Interdecadal Pacific Oscillation) (Liu, 2012). It has considerable impacts on the summer monsoon system. As previous studies investigated, the AMO-related SSTAs show a basin-wide warming/cooling in the North Atlantic, with tropical and extratropical branches centered over the tropical North 

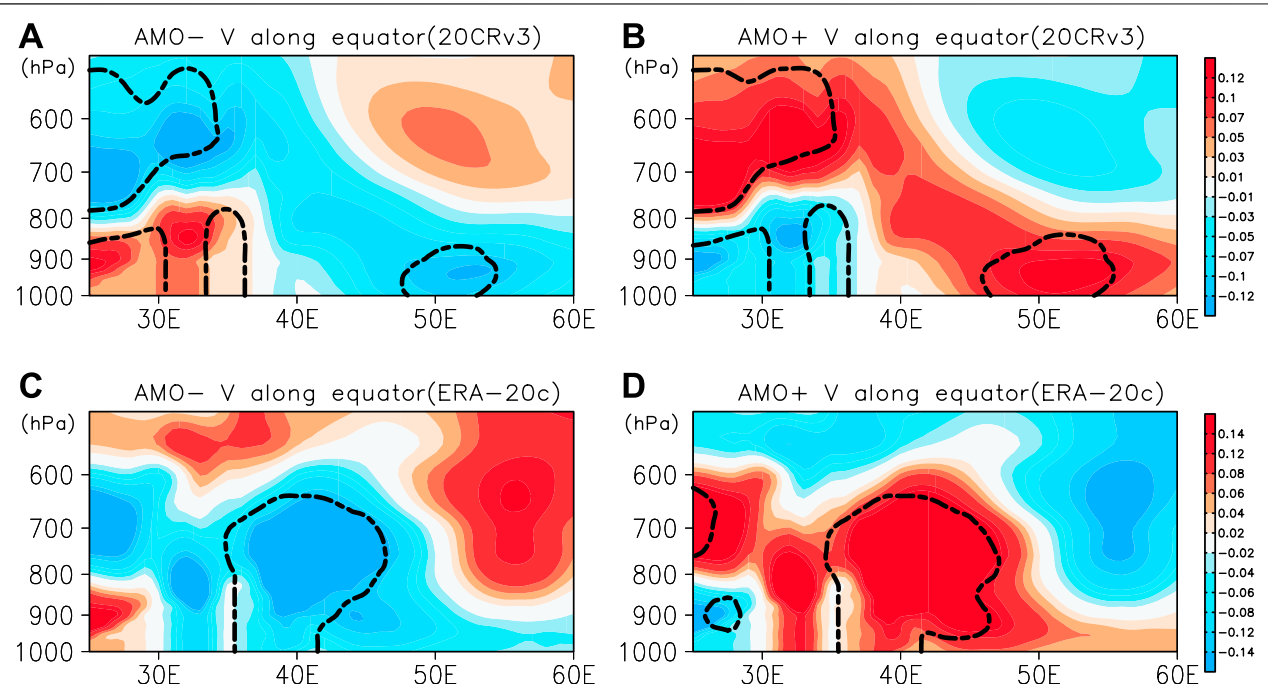

FIGURE 4 | A composite of the zonal mean meridional wind anomalies (unit: $\mathrm{m} \mathrm{s}^{-1}$ ) below $500 \mathrm{hPa}$ along the equator in summer during (A,C) AMO- and (B,D) AMO + periods from the (A,B) 20CRv3 and (C,D) ERA-20c datasets. Areas covered by dashed contours denote values that attained the $90 \%$ significance level. AMO, Atlantic Multidecadal Oscillation; 20CRv3, Twentieth Century Reanalysis dataset, version 3; ERA-20c, European Centre for Medium-Range Weather Forecasts 20th-century reanalysis.

TABLE 4 | Composite values of the summer SAHI (unit: gpm) and SAHA (unit: grids) in warm/cold AMO phase, as well as their difference from the 20CRv3 and ERA-20c datasets during the period of 1900-2010.

\begin{tabular}{lccccc}
\hline & \multicolumn{3}{c}{ SAHI (gpm) } & \multicolumn{2}{c}{ SAHA (grids) } \\
\hline 2OCRv3 & AMO- & AMO+ & Difference & AMO- & AMO+ \\
ERA-2OC & $\mathbf{6 6 5 , 8 0 3 . 4}$ & $\mathbf{7 9 7 , 1 2 5 . 1}$ & $\mathbf{1 3 1 , 3 2 1 . 7}$ & $8,124.73$ & $8,883.73$ \\
\end{tabular}

Note. The bold data denote values that attained the $95 \%$ significance level.

SAHI, intensity of the South Asian High; SAHA, South Asian High area; AMO, Atlantic Multidecadal Oscillation; 20CRv3, Twentieth Century Reanalysis dataset, version 3; ERA-20c, European Centre for Medium-Range Weather Forecasts 20th-century reanalysis.
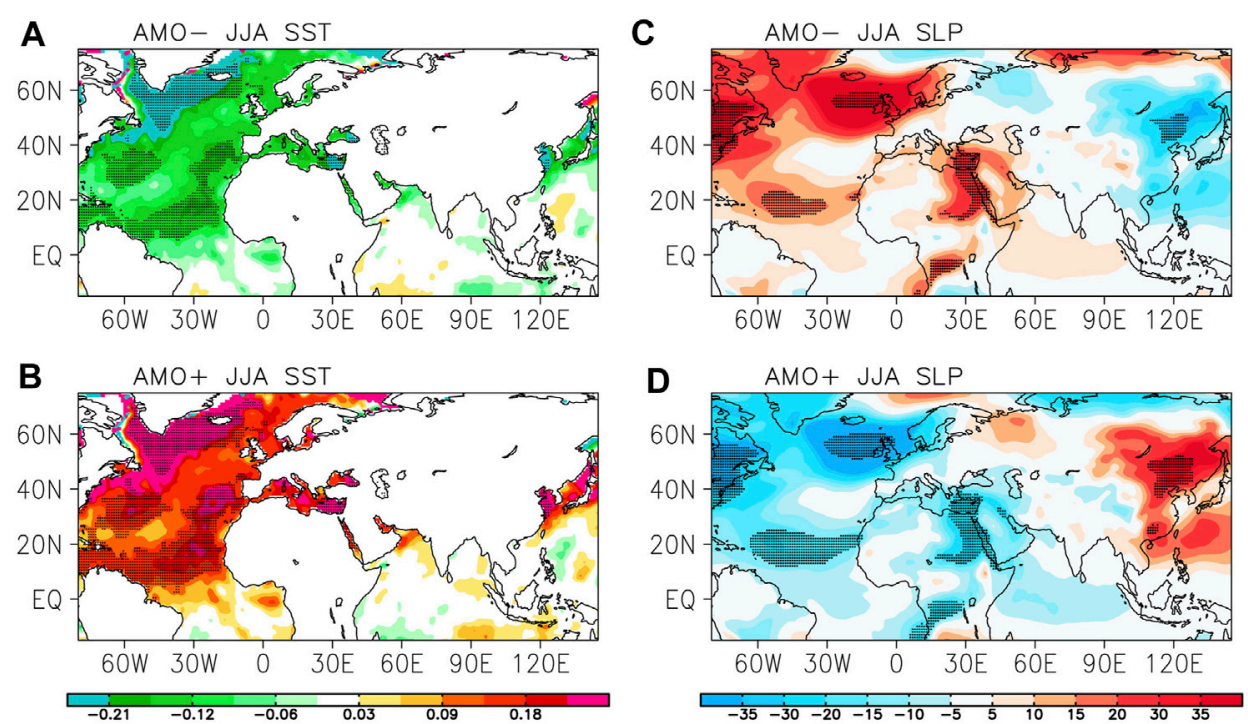

FIGURE 5 |A composite of the summer (A,B) SST anomalies (unit: $\left.{ }^{\circ} \mathbf{C}\right)$ and (C,D) sea level pressure anomalies (Pa) over the northern Atlantic Ocean during (A,C) AMO- and (B,D) AMO+ periods from the ERA-20c dataset during the period 1900-2010. Dots denote values that attained the 95\% significance level. SST, sea surface temperature; AMO, Atlantic Multidecadal Oscillation; ERA-20c, European Centre for Medium-Range Weather Forecasts 20th-century reanalysis. 

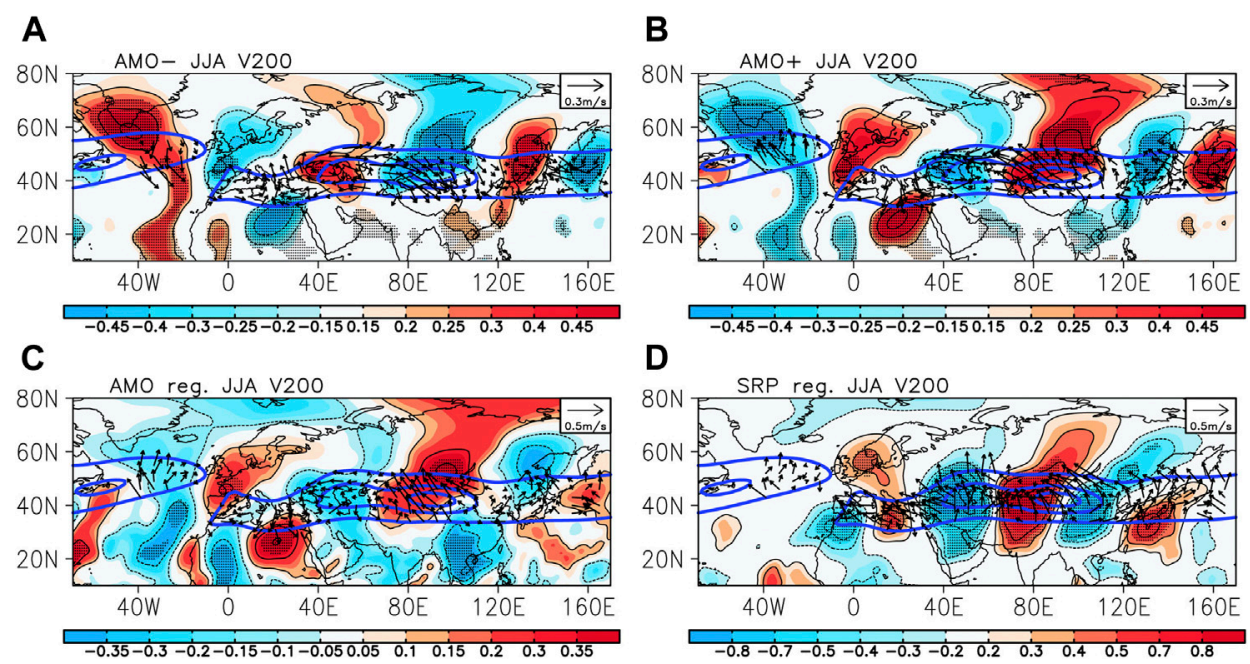

FIGURE 6 |A composite of the 200-hPa meridional wind (V200) anomalies (color shading; unit: $\mathrm{m} \mathrm{s}^{-1}$ ) and the horizontal component of the wave activity flux (arrow; unit: $\mathrm{m}^{2} \mathrm{~s}^{-2}$ ) in summer during (A) AMO- and (B) AMO+ periods. Regressions of the interdecadal component of the summer 200-hPa meridional wind anomalies (color shading; units: $\mathrm{m} \mathrm{s}^{-1}$ ) and horizontal wave activity fluxes (arrow; unit: $\mathrm{m}^{2} \mathrm{~s}^{-2}$ ) onto the interdecadal component of the summer (C) AMO and (D) SRP index from the ERA20 c datasets during the period 1900-2010. The blue solid contours are climatological 200-hPa zonal wind in summer (units: $\mathrm{m} \mathrm{s}^{-1}$ ). Contour intervals are \pm 0.2 , \pm 0.4 , and $\pm 0.6 \mathrm{~m} \mathrm{~s}^{-1}$ (A,B,D) and $\pm 0.1, \pm 0.3$, and $\pm 0.5 \mathrm{~m} \mathrm{~s}^{-1}$ (C). Dots denote values that attained the $90 \%$ significance level. AMO, Atlantic Multidecadal Oscillation; SRP, Silk Road pattern; ERA-20c, European Centre for Medium-Range Weather Forecasts 20th-century reanalysis.

Atlantic and Labrador Sea, respectively (e.g., Sutton and Hodson, 2005; Gastineau and Frankignoul, 2015). Figures 2B-I show regressions of the interdecadal SST component onto the interdecadal component of the SMJI and PC1 in summer from the different datasets. The AMO-like regression SST patterns are seen from the northern Atlantic Ocean in the JRA-55, 20CRv3, and ERA-20c datasets. In contrast, the AMO-like SSTAs are much weaker in the NCEP/NCAR dataset than those in the other datasets. This analysis reveals a positive correlation of the AMO with the SAHI and SMJI in an interdecadal timescale. A remarkable feature of the AMO index in the latest 100 years is that the AMO has experienced three cold-warm phase turnings, with the turning points in near mid-1920s, 1960s, and mid-1990s (Figure 2A). Comparing Figures 1F,H and Figure 2A, it is easy to find that these three indices (PC1, SMJI, and AMO) evolve almost synchronously on multidecadal timescales, with the two AMO cold phases (AMO-) for a period of 59 years (1900-1925 and 1963-1995) corresponding to the weak phases for the SAH and SMJ, and the two warm AMO phases (AMO+) for 52 years (1926-1962 and 1996-2010) corresponding to the strong phases for the SAH and SMJ.

\section{Variations of the Wind and Geopotential High Fields}

In the following, we further conduct a composite analysis of the summer 925-hPa wind anomalies, 200-hPa geopotential height anomalies, and zonal mean meridional wind anomalies below $500 \mathrm{hPa}$ along equator for AMO- years (1900-1925 and 1963-1995) and AMO+ years (1926-1962 and 1996-2010). The blue and pink solid contours in Figure 3 represent the composited ridge lines (i.e., 12,500- or 12,400-gpm contours of the 200-hPa geopotential height) of the summer SAH for the AMO- and AMO+ years, respectively. Figures 3E,F show that significant northwesterly/southeasterly anomalies appear over the western Indian Ocean between $0^{\circ}$ and $25^{\circ} \mathrm{S}$ for AMO-/ $\mathrm{AMO}+$ years in the ERA-20c dataset, indicating marked weakening/strengthening of the SMJ in the AMO cold/warm phase. This is also announced by northerly/southerly wind anomalies for the AMO-/AMO+ phase from the ERA-20c dataset at $40^{\circ} \mathrm{E}$ below $600 \mathrm{hPa}$, which is the domain region of the SMJ, with its maximum center occurring between 800 and $700 \mathrm{hPa}$ (Figures 4C,D). The significant northerly/southerly anomalies from the Arabian Sea to the Southern Indian Ocean are also seen from the 925-hPa wind anomalies composite of the 20Rv3 dataset (Figures 3A,B). The northerly/southerly wind anomalies exceeding 90\% confidence level for AMO-/AMO+ phase in the $20 \mathrm{CRv} 3$ dataset are also found at $50^{\circ} \mathrm{E}$ below $800 \mathrm{hPa}$. Furthermore, associated with the AMO cold/warm phase, largescale negative/positive geopotential height anomalies at $200 \mathrm{hPa}$ are seen from Figures 3C,D,G,H with significant values over Northeast Asia and the Mediterranean Sea and extending from the Arabian Peninsula to the Bay of Bengal. In comparison, the significant height anomaly area from the 20CRv3 dataset, which extends from the Northern Africa to the northwestern Pacific Ocean is substantially larger than that from the ERA-20c dataset. The above evidences indicate that when the AMO is in the cold (warm) phase, the summer SAH tends to weaken and shrink (intensify and expand) as revealed by the composited ridge lines and the composites of the SAH intensity and area calculated in Table 4. The quantitative analyses in Table 4 clearly show that the differences of the SAH area and intensity between the warm and cold AMO phases from both 20CRv3 and ERA-20c datasets are significant and exceed the 95\% confidence level. 

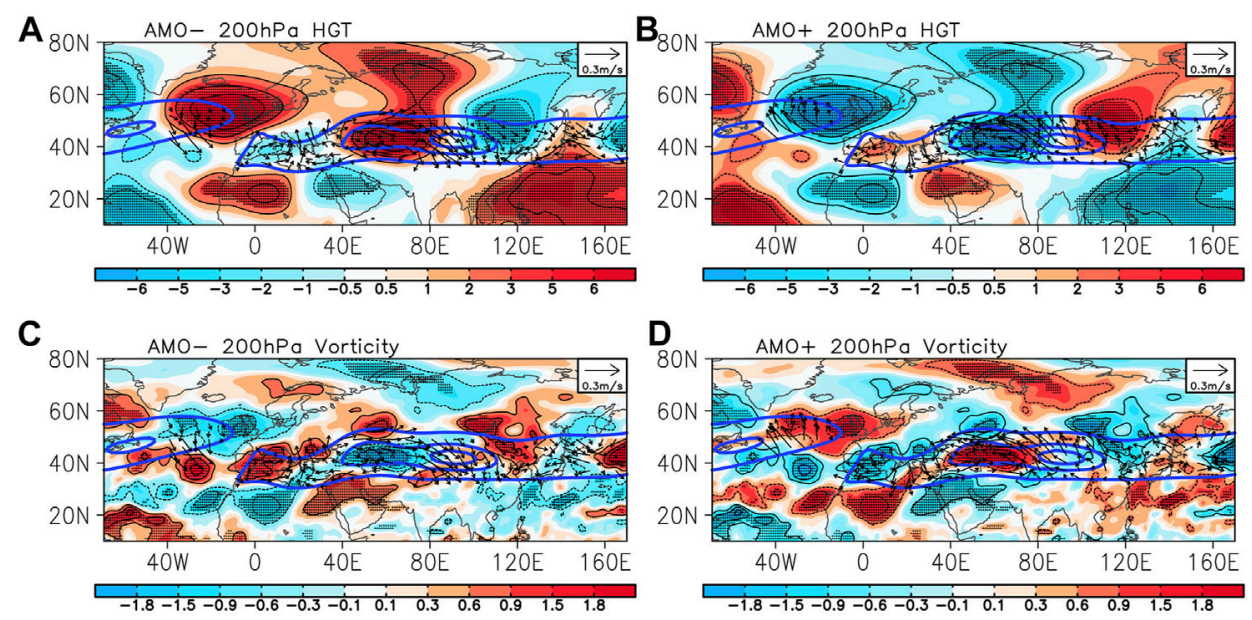

FIGURE 7|A composite of (A,B) the departure from zonal mean 200-hPa geopotential height (HGT) anomalies (color shading; unit: gpm) and (C,D) the 200-hPa relative vorticity anomalies (color shading; unit: $10^{-6} \mathrm{~s}^{-1}$ ) with the horizontal wave activity flux (arrow; unit: $\mathrm{m}^{2} \mathrm{~s}^{-2}$ ) in summer during (A) AMO- and (B) AMO+ periods from the ERA-20c datasets during the period 1900-2010. The blue solid contours are climatological 200-hPa zonal wind in summer (units: $\mathrm{m} \mathrm{s}^{-1}$ ). Contour intervals are $\pm 2, \pm 4$, and $\pm 6 \mathrm{gpm}$ (A,B) and $\pm 0.6, \pm 1.2$, and $\pm 1.8 \times 10^{-6} \mathrm{~s}^{-1}$ (C,D). Dots denote values that attained the $90 \%$ significance level. AMO, Atlantic Multidecadal Oscillation; ERA-20c, European Centre for Medium-Range Weather Forecasts 20th-century reanalysis.
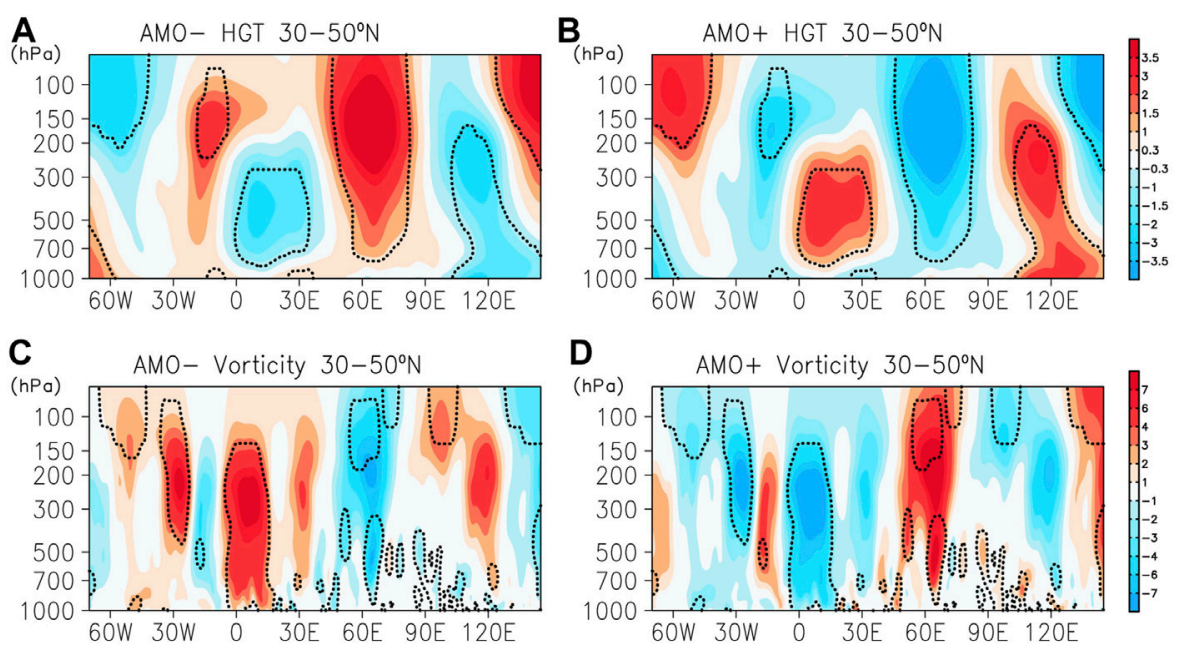

FIGURE 8|A composite of the (A,B) zonal mean $\left(30^{\circ}-50^{\circ} \mathrm{N}\right)$ geopotential height anomalies (departures from zonal means; unit: gpm) and $(\mathbf{C}, \mathbf{D})$ the relative vorticity anomalies (color shading; unit: $10^{-6} \mathrm{~s}^{-1}$ ) in summer during (A,C) AMO- and (B,D) AMO+ periods from the ERA-20c dataset during the period 1900-2010. Areas covered by dotted contours denote values that attained the 90\% significance level. AMO, Atlantic Multidecadal Oscillation; ERA-20c, European Centre for MediumRange Weather Forecasts 20th-century reanalysis.

\section{MODULATION MECHANISM OF THE SUMMER SOUTH ASIAN HIGH AND SOMALI JET BY THE ATLANTIC MULTIDECADAL OSCILLATION ON AN INTERDECADAL TIMESCALE}

The previous section illustrated that the interdecadal variabilities of the SAH and SMJ in summer were closely associated with the
AMO. In the following, we extend our investigation into how the variations of the SAH and SMJ on the interdecadal timescale are modulated by the AMO phase.

\section{Interdecadal Silk Road Pattern-Like Wave Train}

To investigate the effects of the AMO phases on the intensity of the SAH and SMJ on the interdecadal timescale, a composite 

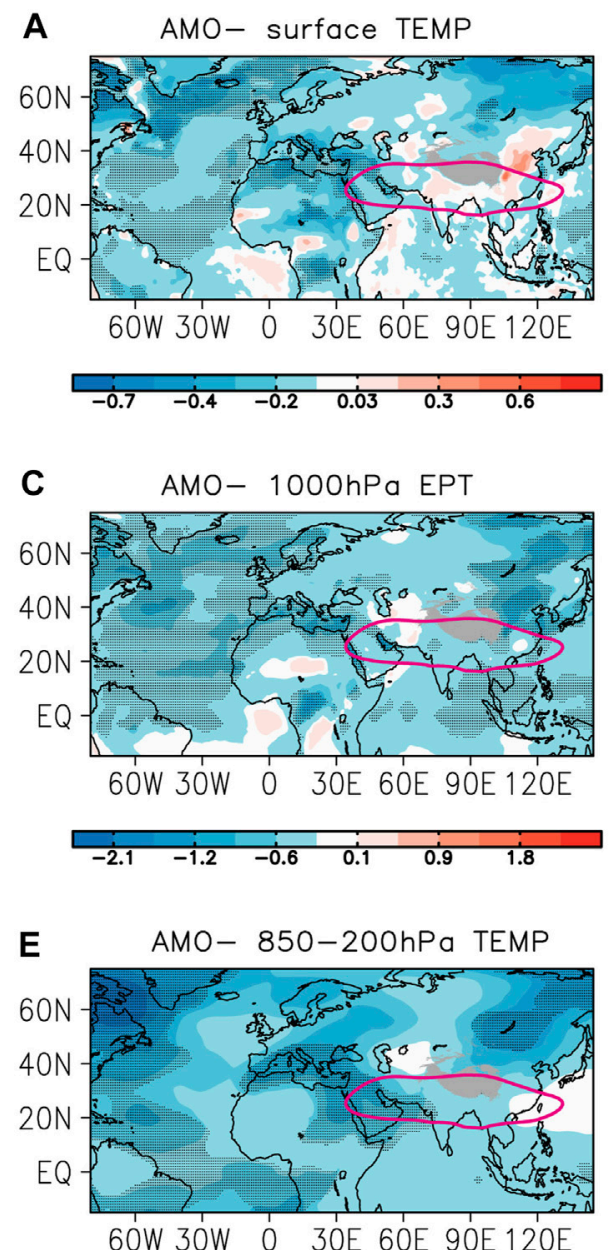

60W 30W 0 30E 60E 90E 120E

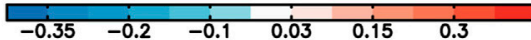

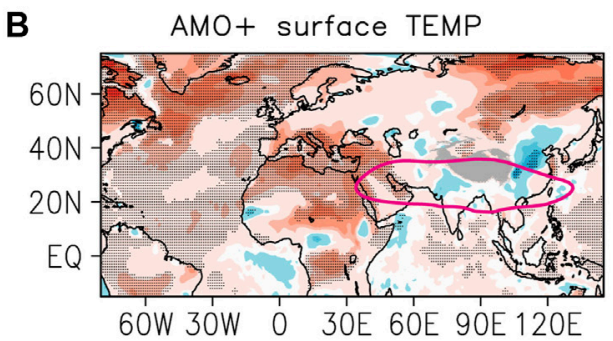
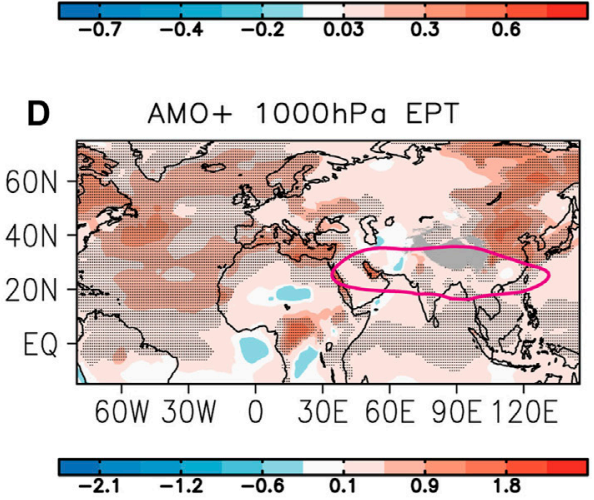

F $\quad \mathrm{AMO}+850-200 \mathrm{hPa}$ TEMP

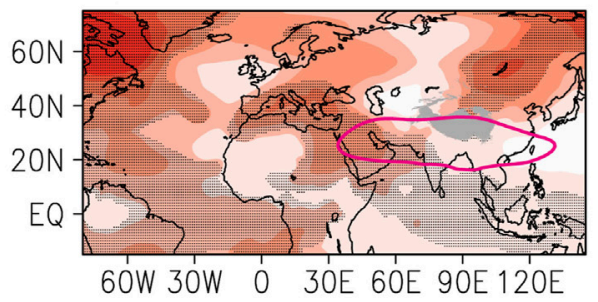

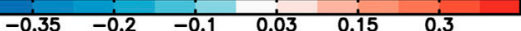

FIGURE 9|A composite of the summer (A,B) surface air temperature anomalies (unit: ${ }^{\circ} \mathrm{C}$ ), (C,D) equivalent potential temperature anomalies (unit: ${ }^{\circ} \mathrm{C}$ ) at 1,000 hPa, and (E,F) tropospheric temperature anomalies (unit: ${ }^{\circ} \mathrm{C}$ ) during (A,C,E) AMO- and (B,D,F) AMO+ periods from the ERA-20c dataset during the period 1900-2010. Dots denote values that attained the $90 \%$ significance level. Shadings in gray indicate the Tibetan Plateau region. The pink contour denotes the climatological isoline of 12,400 gpm at $200 \mathrm{hPa}$ in summer. AMO, Atlantic Multidecadal Oscillation; ERA-20c, European Centre for Medium-Range Weather Forecasts 20th-century reanalysis.

analysis is performed on the lower and upper atmospheric circulations for the $\mathrm{AMO}-$ and $\mathrm{AMO}+$ periods. Figure 5 illustrates the composites of the SSTAs over the northern Atlantic Ocean and SLP anomalies in summer during the $\mathrm{AMO}-$ and $\mathrm{AMO}+$ periods for the ERA-20c dataset during the period of 1900-2010. In the AMO- phase, the negative SSTAs are clearly seen over nearly the whole northern Atlantic Ocean region. Two significant value branches centered over the tropical North Atlantic and Labrador Sea. However, remarkable positive SLP anomalies are located near $20^{\circ} \mathrm{N}$ and $60^{\circ} \mathrm{N}$ of the Atlantic Ocean, as well as around the west of the Arabian Peninsula. Clearly, the large-scale negative SLP anomalies appear in Northeast Asia. In the AMO+ phase, the result is well similar to that in the AMO- but with the opposite sign. The tropical and extratropical branches of the SSTAs are coinciding with the location of the SLP anomalies over the northern Atlantic Ocean. It seems that the cold/warm Atlantic Ocean SSTAs could promote/reduce SLP anomalies over the tropical and extratropical Atlantic Ocean because of the atmospheric instability. Significantly, the SLP anomalies around the west of the Arabian Peninsula weaken/enhance the SLP gradient between the tropical Indian Ocean and the continent to its northwest, which will mainly contribute to the decreased/reinforced SMJ strength on the interdecadal timescale as shown in Figures 3E,F.

Along the Asian westerly jet, there is a wave train-like teleconnection pattern zonally propagating from Europe to East Asia. This pattern is referred to as the SRP, which is similar to the CGT over the Eurasian continent (e.g., Ding and Wang, 2005; Hong et al., 2018). The SRP, the leading mode of the upper tropospheric meridional wind anomalies in summer (e.g., Hong and Lu, 2016; Kosaka et al., 2009; Sato and Takahashi, 2006; Cen et al., 2020), indicates both a remarkable interannual component and a considerable decadal component (e.g., Enomoto et al., 2003; Lu et al., 2002; Sato and Takahashi, 

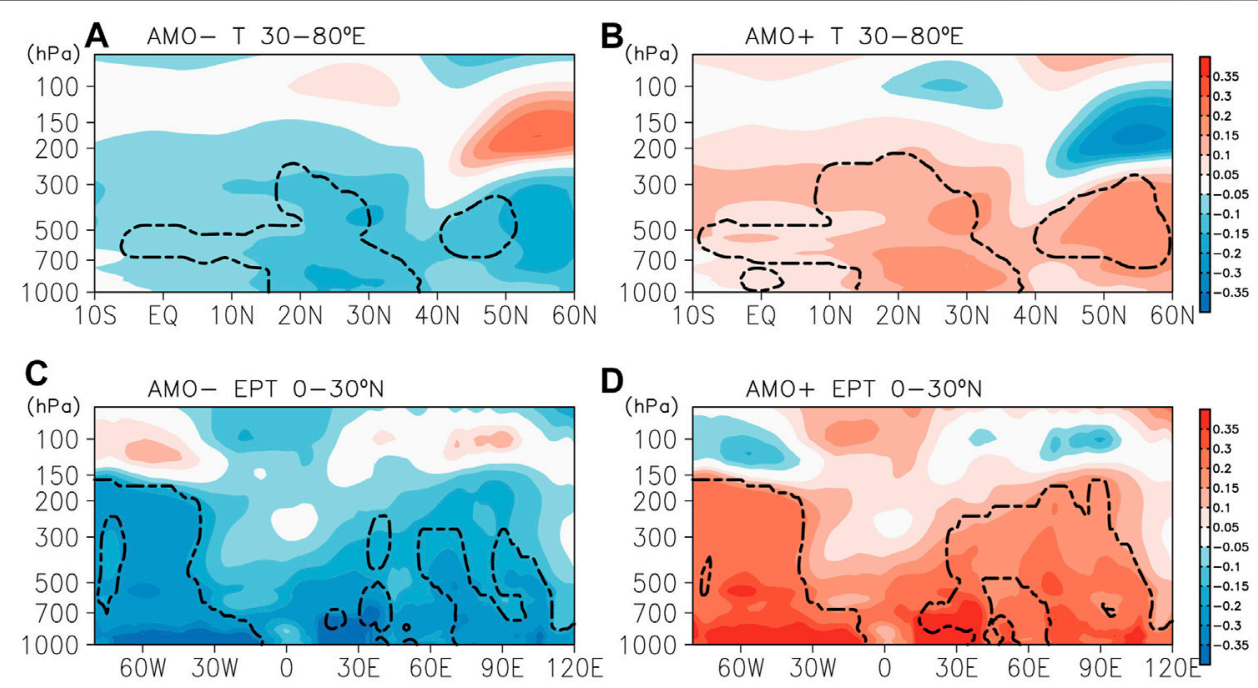

FIGURE 10 1 A composite of (A,B) the meridional mean $\left(30^{\circ}-80^{\circ} \mathrm{E}\right)$ air temperature anomalies (unit: $\left.{ }^{\circ} \mathrm{C}\right)$ and $(\mathbf{C}, \mathbf{D})$ the zonal mean $\left(0^{\circ}-30^{\circ} \mathrm{N}\right)$ equivalent potential temperature anomalies (unit: ${ }^{\circ} \mathrm{C}$ ) in summer during (A,C) AMO- and (B,D) AMO+ periods from the ERA-20c dataset during the period 1900-2010, respectively. Areas covered by dashed contours denote values that attained the $90 \%$ significance level. AMO, Atlantic Multidecadal Oscillation; ERA-20c, European Centre for MediumRange Weather Forecasts 20th-century reanalysis.

2006; Hong et al., 2018; Wang et al., 2017; Lin et al., 2016). The temporal evolution in the interdecadal component of the SRP was found to be synchronous with that in the AMO. Based on sensitivity experiments driven by the specified AMO-related SSTAs in the North Atlantic using five AGCMs, Lin et al. (2016) suggested that ID-CGT pattern should be excited, at least partially, by the AMO-related SSTAs. To confirm this, Figures 6A,B illustrate composites of the summer $200-\mathrm{hPa}$ meridional wind anomalies and the summer horizontal wave activity flux during the AMO- and AMO+ phases for 1900-2010. The wind anomalies appear as a clear wave-like pattern characterized by alternate southerly and northerly anomalies along the Asian westerly jet (the blue solid contours in Figure 6). The midlatitude wave train is consistent with the interdecadal component of SRP as announced by various previous studies (e.g., Chen and Huang, 2012; Hong and Lu, 2016; Kosaka et al., 2009; Lu et al., 2002; Sato and Takahashi, 2006; Yasui and Watanabe, 2010). For the AMO- period, southerly anomalies are centered over the tropical North Atlantic, Labrador Sea, Caspian Sea, and northeast Asian and northerly anomalies around the East Europe, North Africa, Lake Belga, and east of the Okhotsk Sea (Figure 6A). The wave activity flux (Takaya and Nakamura 2001) associated with the AMOphase emanates from Europe, enters the Asian jet stream near the Caspian Sea, and points continuously eastward toward East Asia along the jet stream, confirming that the wave-like pattern is a Rossby wave train. For the AMO+ period, locations and amplitudes of the anomalous centers tend to be similar but with the opposite phase (Figure 6B). To further confirm whether this AMO-related wave-like pattern is similar to the interdecadal SRP, we then compare the regression of the interdecadal component of the summer 200-hPa meridional wind and horizontal wave activity flux anomalies onto the interdecadal component of the summer AMO and SRP indices in Figures 6C,D. Clearly, the alternate southerly and northerly anomalous centers along the Asian westerly jet are essentially consistent in Figures 6C,D, except for the anomalies over the northern Atlantic Ocean. Both regressions of the horizontal wave activity flux anomalies in Figures 6C,D are propagating from East Asian to Europe along the jet stream, which reveals the warm AMO phase corresponding to the negative phase of the SRP. Similar results are obtained by Wang et al. (2017), and they also suggest that the positive (negative) phase of the AMO significantly facilitates the occurrence of a negative (positive) phase of the interdecadal SRP (e.g., figure 9B and figures 11A,B of Wang et al., 2017). The spatial similarity coefficient between the regression of the interdecadal $200-\mathrm{hPa}$ meridional wind onto the AMO index (Figure 6C) and that onto the SRP index (Figure 6D) in the main SRP region $\left(30^{\circ}-60^{\circ} \mathrm{N}, 30^{\circ}-130^{\circ} \mathrm{E}\right)$ is as high as 0.72 , indicating that the AMO-related wave-like pattern is a SRP-like wave train.

Figure 7 is the same as Figure 6, but for the summer 200-hPa geopotential height anomalies (departures from zonal means), 200-hPa relative vorticity anomalies, and horizontal wave-activity flux anomalies. In the AMO- phase, a well-organized wave train between $30^{\circ} \mathrm{N}$ and $60^{\circ} \mathrm{N}$ propagates along the Asian westerly jet (the blue solid contours in Figure 7) with positive geopotential height/negative relative vorticity anomalies over the northern Atlantic Ocean and east of the Caspian Sea and negative geopotential height/positive relative vorticity anomalies over the Mediterranean Sea, Arabian Peninsula-Iranian Plateau, and Northeast Asia (Figures 7A,C). These positive and negative anomalies are consistent with the $200-\mathrm{hPa}$ meridional wind anomalies shown in Figure 6A. Actually, this atmospheric wave train originated from the extratropical Atlantic Ocean, which can be confirmed by the wave activity flux (Figure 7A). This suggests that in virtue of the strong barotropic instability at the jet exit region over the North Atlantic during the 

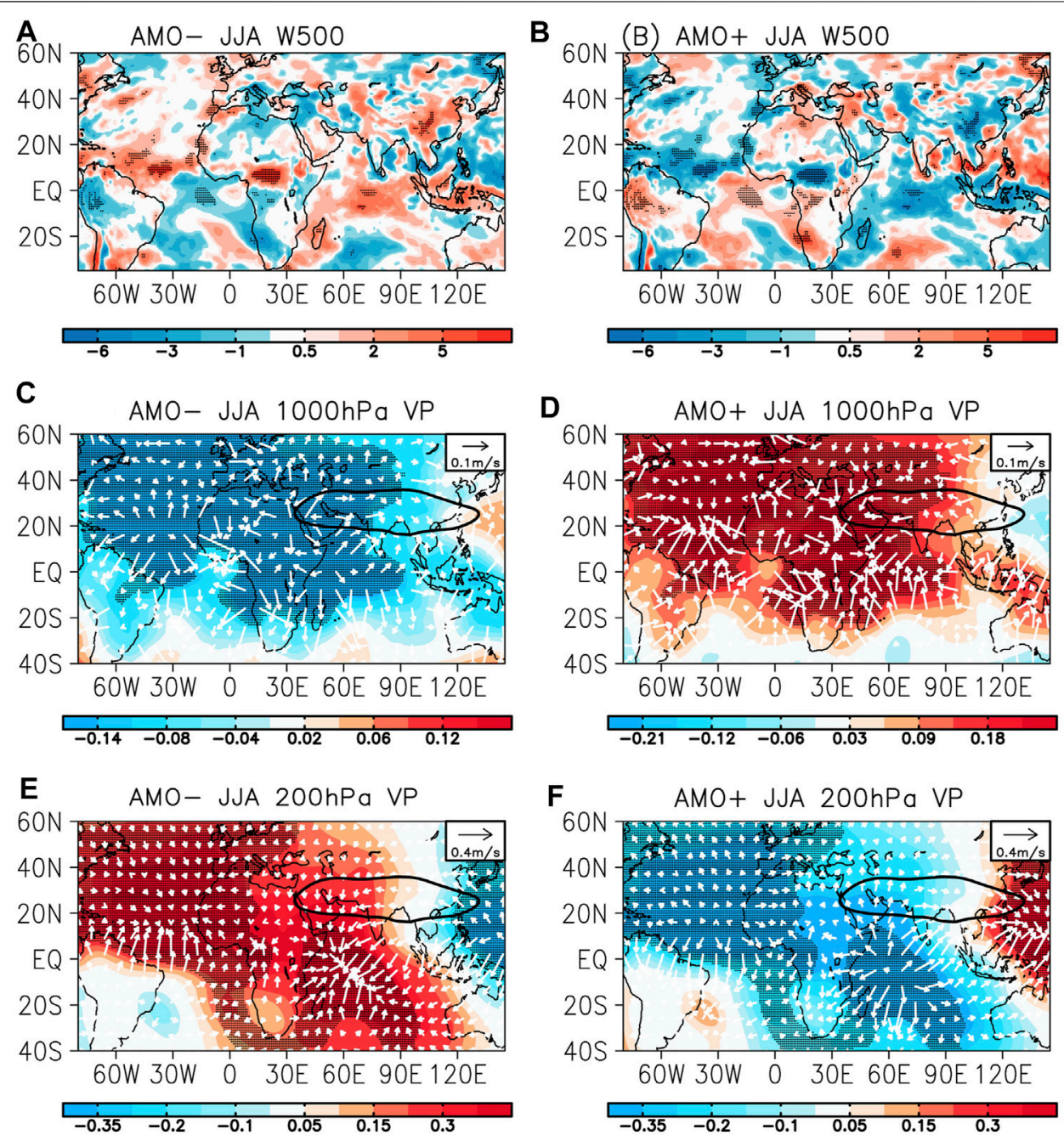

FIGURE 11 | A composite of (A,B) the 500-hPa omega $\left(10^{-3} \mathrm{~Pa} \mathrm{~s}^{-1}\right)$ anomalies, the (C,D) 1,000-hPa and (E,F) 200-hPa divergent winds (arrow, $\left.\mathrm{m} \mathrm{s}^{-1}\right)$, and stream function (shadings, $10^{-4} \mathrm{~m}^{2} \mathrm{~s}^{-1}$ ) anomalies in summer during (A,C,E) AMO- and (B,D,F) AMO+ periods from the ERA-20c dataset during the period 1900-2010. Dots denote values that attained the 90\% significance level. AMO, Atlantic Multidecadal Oscillation; ERA-20c, European Centre for Medium-Range Weather Forecasts 20th-century reanalysis.

AMO- phase, an anomalous high can be triggered over the extratropical Atlantic Ocean, followed by alternatively positive and negative anomalies further downstream. The consistent positive anomalies over the extratropical Atlantic Ocean and negative anomalies over Northeast Asia in SLP with those in 200-hPa geopotential height reveal a barotropic structure. The barotropic property of the Rossby wave train on interdecadal timescale as suggested by previous studies (Luo et al., 2011; Lin et al., 2016; Hong et al., 2018) also can be revealed by the zonal mean height/relative vorticity from $30^{\circ} \mathrm{W}$ to $120^{\circ} \mathrm{E}$ in Figure 8 . The barotropy of the cyclonic/anticyclonic centers between $0^{\circ}$ and $30^{\circ} \mathrm{E}$ in the $\mathrm{AMO}-/ \mathrm{AMO}+$ phase is relatively weak in the geopotential height field (Figures $\mathbf{8 A , B}$ ), but it is strong and significant in the relative vorticity field (Figures 8C,D). As suggested by Hoskins et al. (1977), the relative vorticity has some advantages over geopotential height in representing the two-dimensional propagation of Rossby waves.
As indicated by the wave activity flux, the interdecadal SRPlike wave train excited by the cold SST anomalies over the extratropical Atlantic Ocean propagates poleward across Europe and then to the equator across Northeast Asia. Specifically, the negative 200-hPa geopotential height/positive $200-\mathrm{hPa}$ relative vorticity anomalies from the Mediterranean Sea to the Arabian Peninsula corresponding to the positive SLP anomalies around the west of the Arabian Peninsula indicate a strong baroclinicity of the local atmospheric circulation, which is favorable to the weakening of the SAH and SMJ. Meanwhile, the strong and significant anomalies over the northwest Pacific Ocean in the geopotential height field (departure from zonal mean) are relatively weak and insignificant in the original geopotential height (Figures 3G,H) and relative vorticity fields (Figures 7C,D), which suggests that the weakening or strengthening of the summer SAH mainly rely on the low/high anomaly from the Arabian 


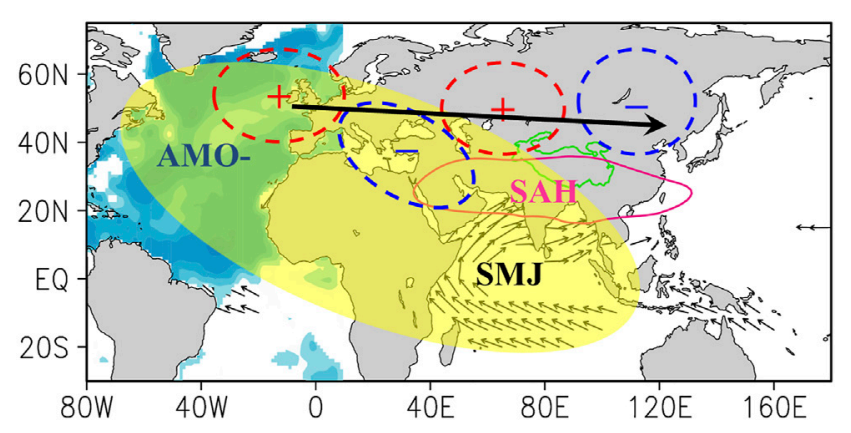

FIGURE 12 |Schematic diagram illustrates modulation mechanism of the summer SAH and SMJ interdecadal variabilities by the AMO- phase via the interdecadal Silk Road pattern and Matsuno-Gill-like tropical atmospheric response. Blue shading over North Atlantic denotes the negative SST anomalies related to AMO- phase. Red circle and blue circle respectively represent the positive and negative anomalies of 200-hPa geopotential heights in AMO-phase. The black solid line with an arrow is the propagation path of the interdecadal Silk Road pattern. The pink contour denotes the climatological location of the SAH in summer. The black arrows indicate the summer SMJ. Contour in green indicates the Tibetan Plateau region. SAH, South Asian High; SMJ, Somali jet; AMO, Atlantic Multidecadal Oscillation; SST, sea surface temperature.

Peninsula to the Bay of Bengal (Figures 3G,H). In the AMO+ phase, a similar Rossby wave train pattern propagating from the North Atlantic across Northeast Asia is visible (Figures 7B,D), but with a quite opposite phase. The above result indicates that a propagating Rossby wave train associated with the AMO-/ $\mathrm{AMO}+$ phase leads to reduced/enhanced $\mathrm{SAH}$ via the anomalous Arabian Peninsula-Iranian Plateau low/high along with its path, and consequently a weakening/strengthening of the SMJ through the weakened/enhanced pressure gradient between the tropical Indian Ocean and the continent, which is caused by the baroclinic structure of the local atmospheric circulation over the Arabian Peninsula-Iranian Plateau (Figures 5C,D).

\section{Tropical Atmospheric Response}

By now, we have clearly demonstrated the modification of AMOrelated SSTAs on the interdecadal variabilities of the SAH and SMJ intensities through the propagation of the interdecadal SRPlike wave train excited by the extratropical heating branch. As diagnosed in Figures 5A,B, the tropical heating branch related to the AMO phase cannot be ignored, but how it can exert influence on the interdecadal variabilities of SAH and SMJ intensities is still unclear. To investigate the tropical atmospheric response to AMO-related SST anomalies, we conducted a composite analysis of SAT anomalies, equivalent potential temperature (EPT) anomalies at $1,000 \mathrm{hPa}$, and tropospheric temperature anomalies (average between 850 and $200 \mathrm{hPa}$ ) in summer during the AMO- and AMO+ periods (Figure 9). For the summer SAT, significant negative temperature anomalies exist over the tropical and extratropical North Atlantic, as well as the northern African continent and Central Siberia area in AMO-, but there are obvious positive anomalies over these domains in the AMO+. The response of the EPT anomalies at $1,000 \mathrm{hPa}$ is the same as that of the SAT, but with the significant value around the Central Siberia area, which expands southward to the tropical Indian Ocean, which is a result of the Matsunuo-Gill response of the tropical atmosphere. For the tropospheric temperature (average between 850 and $200 \mathrm{hPa}$ ), the temperature response exhibits a Matsunuo-Gill-like pattern with uniform negative/ positive values zonally extending to the entire tropical region in the AMO-/AMO+ phase. Qian et al. (2002) pointed out that the center of the SAH has the heat preference property, which is usually located over or moving toward an area with larger heating rates. Huang et al. (2011) also indicated that tropical tropospheric temperature variation is closely related to geopotential height anomalies at the upper troposphere and variation of the SAH in terms of both intensity and spatial location. The tropospheric warming over the tropical Indian Ocean is favorable for a positive height anomaly in the south of the SAH location in summer, which results in the strengthening and southward shifting of the $\mathrm{SAH}$. According to the barometric equation, the negative/positive AMO-related tropical SSTAs cool/warm the tropospheric temperature in the south of the SAH location and then lower/ elevate the height above it, which is favorable for the weakening/ strengthening and northward/southward expansion of the SAH.

Besides, pronounced anomalies are found around the western Atlantic Ocean, northeast Asia, Mediterranean Sea, and Arabian Peninsula, which mainly result from the interdecadal SRP-like wave train triggered by the extratropical AMO-related SST anomalies. Among them, the significant negative/positive temperature anomalies from the Mediterranean Sea to the Arabian Peninsula could decrease/increase meridional gradient of the tropospheric temperature between the tropical Indian Ocean and its north continent. The increased meridional gradient anomalies of the tropospheric temperature over the tropical Indian Ocean associated with the AMO+ could enhance the SMJ. This mechanism coincides with previous works (Goswami et al., 2006; Feng and Hu, 2008; Li et al., 2008; Luo et al., 2011), which viewed that the ISM may be enhanced by the AMO through the increased meridional gradient of the tropospheric temperature between the Indian subcontinent and tropical Indian Ocean. To provide more evidence, the composite of the meridional mean $\left(30^{\circ}-80^{\circ} \mathrm{E}\right)$ air temperature anomalies in summer during the AMO- and AMO+ periods is investigated in Figures 10A,B. In AMO-, remarkably significant negative values between $20^{\circ} \mathrm{N}$ and $30^{\circ} \mathrm{N}$ could extend to nearly $200 \mathrm{hPa}$, which reduces the meridional gradient of the 
tropospheric temperature between the tropical Indian Ocean and its north continent, as well as consequently weaken the SMJ intensity. The result in the AMO+ phase is exactly opposite to that in AMO-, with stronger positive anomalies at $20^{\circ} \mathrm{N}-30^{\circ} \mathrm{N}$ from the surface to the upper layer, which mainly contribute to the strengthened SMJ.

Next, how can the AMO-related SSTAs or SAT anomalies over the tropical Atlantic Ocean influence the tropical tropospheric temperature anomalies? Many studies viewed that the moist adjustment process was very important for the tropospheric warming in the tropical atmosphere (Emanuel et al., 1994; Su et al., 2003; Su and Neelin, 2003). As verified by Xie et al. (2009), SST warming in the tropical Indian Ocean could warm the overlying atmospheric column through modifying the EPT and moist static energy in the atmospheric boundary layer, with a Matsunuo-Gill response of the tropospheric temperature anomalies located over the Indian Ocean. A qualitatively similar response of the tropical tropospheric temperature anomalies to the AMO-related SSTAs over tropical North Atlantic is seen from Figures 9E,F. Response of the tropospheric temperature to SSTAs in the tropical North Atlantic Ocean exhibits an obvious Matsunuo-Gill-like pattern with the large-scale approximate uniform anomalies covering the whole tropical region. This is also revealed by the zonal mean $\left(0^{\circ}-30^{\circ} \mathrm{N}\right)$ EPT anomalies composed during the AMO- and $\mathrm{AMO}+$ periods in Figures 10C,D. In AMO-, the significant negative EPT anomalies can extend from the surface to more than $200 \mathrm{hPa}$ over the tropical Atlantic Ocean (between $80^{\circ} \mathrm{W}$ and $\left.30^{\circ} \mathrm{W}\right)$. An approximate uniform variation of the EPT anomalies from the lower to upper level is also seen between $30^{\circ}$ and $90^{\circ} \mathrm{E}$. These reveal that the EPT change in the atmospheric boundary layer (seen from Figures 9C,D) induced by AMO-related SSTAs is an important pathway through which the lower atmospheric heat can be transferred to the upper layer, modifying the tropospheric thermal variation. In the $\mathrm{AMO}+$, the result is similar to that in AMO-, but with an opposite sign. In brief, the AMO-related tropical SST cooling (warming) induces negative (positive) EPT variation in the atmospheric boundary layer, modulates air temperature of the overlying atmosphere, and further cools (heats) the atmospheric column.

To better understand the AMO modulation on the interdecadal variabilities of the summer SAH and SMJ intensities via the tropical atmospheric response, we further focus on the composites of the $500-\mathrm{hPa}$ omega anomalies, divergent wind, and velocity potential anomalies at 1,000 and $200 \mathrm{hPa}$ in summer for the AMO- and AMO+ phases (Figure 11). As for the 500-hPa omega anomalies, significant AMO- phase-related subsiding anomalies are found over the northern tropical North Atlantic, southern Sahel, central tropical Indian Ocean, and central East Asia where the reverse signal of vertical velocity can be seen for the AMO+ (Figures 11A,B). Among them, the descending motion anomaly over northern tropical North Atlantic and central East Asia in Figure 11A is mainly associated with a southward shift and weakening of the climatological Intertropical Convergence Zone (ITCZ), which is in accordance with previous results (e.g., Zhang and Delworth, 2006; Luo et al., 2011), while pronounced descending motion anomalies over the southern Sahel of Figure 11A are suggestive of a decreasing Sahel summer rainfall as investigated by Zhang and Delworth (2006). In particular, subsidence motion anomalies over the central tropical Indian Ocean (Figure 11A) correspond to a basin-wide divergence in the lower troposphere and convergence in the upper troposphere over the tropical Indian Ocean during the AMO- period (Figures 11C,E). The tropical Indian Ocean divergence associated with the AMO- phase in the lower troposphere leads to the weakened $\mathrm{SMJ}$, and the tropical Indian Ocean convergence for the AMOphase in the upper troposphere is favorable for the decrease and northward displacement of SAH. Here, the extratropical divergence/convergence over the North Atlantic in the lower/ upper troposphere is produced by the extratropical North Atlantic heating, and the tropical divergence/convergence extending from North Atlantic to the tropical Indian Ocean in the lower/upper troposphere is suggestive of a Matsunuo-Gill-like pattern trigged by tropical North Atlantic heating in agreement with our above result. For the AMO+ phase, the result is quite opposite, which is conducive to the strengthening of the SMJ and SAH in summer (Figures 11B,D,F).

\section{SUMMARY}

Based on four reanalysis datasets (JRA-55, NCEP/NCAR, 20CRv3, and ERA-20c), we investigate the interdecadal variation of the SAH and SMJ intensities, as well as their modulation mechanism by AMO phase-related SSTAs in summer. In order to reveal the temporal variation of the summer SAH, 200-hPa geopotential height anomalies in summer (over $15^{\circ}-40^{\circ} \mathrm{N} ; 20^{\circ}-130^{\circ} \mathrm{E}$ ) are decomposed by an EOF technique. The result shows that the leading spatial pattern of the $200-\mathrm{hPa}$ geopotential height anomalies represents the variation of the $\mathrm{SAH}$ intensity. In contrast, the time series of the PC1 is in phase with that of the SMJI on the interdecadal timescale, with almost all of the correlation coefficients between them from different datasets exceeding the $99 \%$ confidence level. Regressions of the interdecadal SST component onto the interdecadal SMJI and PC1 component in summer from the different datasets reveal a positive correlation of the AMO with the SAHI and SMJI. Besides, through comparing the time series of the AMO index with that of the PC1 and SMJI, we find that these three indices (PC1, SMJI, and AMO) evolve almost synchronously on multidecadal timescales, with the two AMO cold phases (AMO-) for a period of 59 years (1900-1925 and 1963-1995) corresponding to the weak phases for the SAH and SMJ, and the two warm AMO phases (AMO+) for 52 years (1926-1962 and 1996-2010) corresponding to the strong phases for the SAH and SMJ. The composite analysis of the summer 925$\mathrm{hPa}$ wind and 200-hPa geopotential height anomaly fields in the $\mathrm{AMO}-/ \mathrm{AMO}+$ phase also supports this result.

The qualitative analysis shows that the interdecadal variabilities of the SAH and SMJ intensities in summer may be modulated by the AMO phase. Next, the tropical and extratropical atmospheric circulations from the Atlantic Ocean to Northeast Asia are examined to investigate the modulation 
mechanism of the AMO phase on the summer SAH and SMJ intensities. The modulation mechanism appears to be achieved via two ways, which are schematically depicted in Figure 12: one is via an interdecadal SRP-like wave train propagating from the North Atlantic across Northeast Asia, and the other is via a Matsunuo-Gill-like tropical atmospheric response. The former is trigged by extratropical North Atlantic forcing related to the AMO phase, while the latter is tied to the AMO-related tropical North Atlantic heating. On the one hand, as confirmed by the wave activity flux, a cold SST anomaly over extratropical North Atlantic related to the AMO- phase induces an anomalous high over Western Europe due to the strong barotropic instability. The perturbation of geopotential heights gives rise to a well-organized Rossby wave train between $30^{\circ} \mathrm{N}$ and $60^{\circ} \mathrm{N}$ propagating along the Asian westerly jet with positive $200-\mathrm{hPa}$ geopotential height anomalies over the northern Atlantic Ocean and east of the Caspian Sea, as well as negative anomalies from the Mediterranean Sea to the Arabian Peninsula-Iranian Plateau and over Northeast Asia. This interdecadal SRP-like wave train over the Eurasian continent excited by the AMO-related SSTAs have been verified by many previous studies (e.g., Li et al., 2008; Luo et al., 2011; Lin et al., 2016). The anomalous Arabian Peninsula-Iranian Plateau low along with the Rossby wave train path leads to a reduced SAH. On the other hand, the AMOrelated cold SSTAs over tropical North Atlantic reduce the EPT in the boundary layer. Through the moist adjustment process, the tropical tropospheric atmosphere is continuously cooled and produces a Matsuno-Gill-like atmospheric response covering the tropical Indian Ocean, which lowers the geopotential height above it. Because of the heat preference property in $\mathrm{SAH}$, the SAH will weaken and shift northward. At the same time, superimposed cold anomalies from the Mediterranean Sea to the Arabian Peninsula caused by the interdecadal SRP-like wave train reduce meridional gradient of the tropospheric temperature between the tropical Indian Ocean and its north continent, which is favorable for the weakening of the summer

\section{REFERENCES}

Ashfaq, M., Shi, Y., Tung, W.-w., Trapp, R. J., Gao, X., Pal, J. S., et al. (2009). Suppression of South Asian Summer Monsoon Precipitation in the 21st century. Geophys. Res. Lett. 36 (1), L01704. doi:10.1029/2008GL036500

Bjerknes, J. (1964). Atlantic Air-Sea Interaction. Adv. Geophys. 10, 1-82. doi:10.1016/s0065-2687(08)60005-9

Boos, W. R., and Emanuel, K. A. (2009). Annual Intensification of the Somali Jet in a Quasi-Equilibrium Framework: Observational Composites. Q.J.R. Meteorol. Soc. 135, 319-335. doi:10.1002/qj.388

Cadet, D., and Desbois, M. (1981). A Case Study of a Fluctuation of the Somali Jet during the Indian Summer Monsoon. Mon. Wea. Rev. 109, 182-187. doi:10.1175/1520-0493(1981)109<0182:acsoaf $>2.0 . c 0 ; 2$

Cen, S., Chen, W., Chen, S., Liu, Y., and Ma, T. (2020). Potential Impact of Atmospheric Heating over East Europe on the Zonal Shift in the South Asian High: the Role of the Silk Road Teleconnection. Sci. Rep. 10, 6543. doi:10.1038/s41598-020-63364-2

Chakraborty, A., Nanjundiah, R. S., and Srinivasan, J. (2009). Impact of African Orography and the Indian Summer Monsoon on the Low-Level Somali Jet. Int. J. Climatol. 29 (7), 983-992. doi:10.1002/joc.1720

Chen, G., and Huang, R. (2012). Excitation Mechanisms of the Teleconnection Patterns Affecting the July Precipitation in Northwest China. J. Clim. 25 (22), 7834-7851. doi:10.1175/jcli-d-11-00684.1
SMJ. This coincides with previous works (Goswami et al., 2006; Feng and Hu, 2008; Li et al., 2008; Luo et al., 2011). Finally, due to a Matsuno-Gill-like response trigged by tropical North Atlantic heating, subsidence motion anomalies over the central tropical Indian Ocean corresponding to a result in increased lower-level divergence and upper-level convergence are produced over the tropical Indian Ocean. The tropical Indian Ocean divergence in the lower troposphere leads to the weakened summer SMJ, and the tropical Indian Ocean convergence in the upper troposphere is favorable for the decrease and northward displacement of SAH in summer.

\section{DATA AVAILABILITY STATEMENT}

The original contributions presented in the study are included in the article/Supplementary Material, further inquiries can be directed to the corresponding authors.

\section{AUTHOR CONTRIBUTIONS}

WS: Methodology, data curation, manuscript design, and writing-original draft preparation. WS and QW: conceptualization and investigation. ZX: manuscript design and writing-reviewing and editing. WC: writing-reviewing and editing. WD: investigation and data collection.

\section{FUNDING}

This work was jointly supported by the Second Tibetan Plateau Scientific Expedition and Research (STEP) program (2019QZKK0105), the National Natural Science Foundation of China (U1902209, 41930972), and the Key Laboratory of GeoInformation Engineering (SKLGIE2019-ZZ-6).

Compo, G. P., Whitaker, J. S., Sardeshmukh, P. D., Matsui, N., Allan, R. J., Yin, X., et al. (2011). The Twentieth Century Reanalysis Project. Q.J.R. Meteorol. Soc. 137, 1-28. doi:10.1002/qj.776

Dai, W., and Xiao, Z. N. (2014). Multi-Time Scale Variation Characteristics of Somali Jet and its Contact with Precipitation in China. J. Trop. Meteorol. 30 (2), 368-376. doi:10.3969/j.issn.1004-4965.2014.02.018 (in Chinese).

Delworth, T. L., and Mann, M. E. (2000). Observed and Simulated Multidecadal Variability in the Northern Hemisphere. Clim. Dyn. 16, 661-676. doi:10.1007/ s003820000075

Ding, Q., and Wang, B. (2005). Circumglobal Teleconnection in the Northern Hemisphere Summer*. J. Clim. 18 (17), 3483-3505. doi:10.1175/JCLI3473.1

Emanuel, K. A., David Neelin, J., and Bretherton, C. S. (1994). On Large-Scale Circulations in Convecting Atmospheres. Q.J R. Met. Soc. 120, 1111-1143. doi:10.1002/qj.49712051902

Enomoto, T., Hoskins, B. J., and Matsuda, Y. (2003). The Formation Mechanism of the Bonin High in August. Q. J. R. Meteorol. Soc. 129 (587), 157-178. doi:10.1256/qj.01.211

Enomoto, T. (2004). Interannual Variability of the Bonin High Associated with the Propagation of Rossby Waves along the Asian Jet. J. Meteorol. Soc. Jpn. 82, 1019-1034. doi:10.2151/jmsj.2004.1019

Feng, S., and Hu, Q. (2008). How the North Atlantic Multidecadal Oscillation May Have Influenced the Indian Summer Monsoon during the Past Two Millennia. Geophys. Res. Lett. 35, L01707. doi:10.1029/2007gl032484 
Findlater, J. (1969). A Major Low-Level Air Current Near the Indian Ocean during the Northern Summer. Q.J R. Met. Soc. 95 (404), 362-380. doi:10.1002/ qj. 49709540409

Folland, C. K., and Parker, D. E. (1990). "Observed Variations of Sea Surface Temperature," in Climate-Ocean Interaction (Dordrecht: Springer), 21-52. doi:10.1007/978-94-009-2093-4_2

Gastineau, G., and Frankignoul, C. (2015). Influence of the North Atlantic SST Variability on the Atmospheric Circulation during the Twentieth Century. J. Clim. 28, 1396-1416. doi:10.1175/jcli-d-14-00424.1

Goswami, B. N., Madhusoodanan, M. S., Neema, C. P., and Sengupta, D. (2006). A Physical Mechanism for North Atlantic SST Influence on the Indian Summer Monsoon. Geophys. Res. Lett. 33, L02706. doi:10.1029/2005GL024803

Halpern, D., and Woiceshyn, P. M. (2001). Somali Jet in the Arabian Sea, El Niño, and India Rainfall. J. Clim. 14, 434-441. doi:10.1175/1520-0442(2001) 014<0434:sjitas $>2.0$. co;2

He, J., Wen, M., Ding, Y., and Zhang, R. (2006). Possible Mechanism of the Effect of Convection over Asian-Australian "land Bridge" on the East Asian Summer Monsoon Onset. Sci. China Ser. D 49 (11), 1223-1232. doi:10.1007/s11430-0062039-0

Hong, X., and Lu, R. (2016). The Meridional Displacement of the Summer Asian Jet, Silk Road Pattern, and Tropical SST Anomalies. J. Clim. 29 (10), 3753-3766. doi:10.1175/jcli-d-15-0541.1

Hong, X.-W., Xue, S.-H., Lu, R.-Y., and Liu, Y.-Y. (2018). Comparison between the Interannual and Decadal Components of the Silk Road Pattern. Atmos. Oceanic Sci. Lett. 11 (11), 270-274. doi:10.1080/16742834.2018.1439661

Hoskins, B. J., Simmons, A. J., and Andrews, D. G. (1977). Energy Dispersion in a Barotropic Atmosphere. Q.J R. Met. Soc. 103, 553-567. doi:10.1002/qj.49710343802

Hu, J., Zhou, B., and Tao, Li. (2010). Comparative Analysis of the Relation between Characteristic Parameters of South Asia High and Summer Precipitation of China. Meteorol. Mon. 36 (4), 51-56. doi:10.3788/HPLPB20102207.1462 (in Chinese).

Huang, Y., and Qian, Y. (2004). Relationship between South Asian High and Characteristics of Precipitation in Mid- and Lower- Reaches of Yangtze River and North China. Plateau Meteorol. 23, 70-76. (in Chinese). doi:10.3321/j.issn: 1000-0534.2004.01.010

Huang, G., Qu, X., and Hu, K. (2011). The Impact of the Tropical Indian Ocean on South Asian High in Boreal Summer. Adv. Atmos. Sci. 28 (2), 421-432. doi:10.1007/s00376-010-9224-y

Jia, J., and Liu, Y. (2020). Spatial-temporal Characteristics of the Asia High Warm Center and Atmospheric Waves Excited by it in Upper Troposphere. Chin. J. Geophy. 63 (10), 3626-3639. (in Chinese). doi:10.6038/cjg2020N0162

Joseph, P. V., and Raman, P. L. (1966). Existence of Low-Level Westerly Jet Stream over Peninsular India During July. Indian J. Meteorol. Geophys. 17, 407-410.

Kalnay, E., Kanamitsu, M., Kistler, R., Collins, W., Deaven, D., Gandin, L., et al. (1996). The NCEP/NCAR 40-Year Reanalysis Project. Bull. Amer. Meteorol. Soc. 77, 437-471. doi:10.1175/1520-0477(1996)077<0437:tnyrp >2.0.co;2

Kerr, R. A. (2000). A North Atlantic Climate Pacemaker for the Centuries. Science 288, 1984-1985. doi:10.1126/science.288.5473.1984

Knight, J. R., Folland, C. K., and Scaife, A. A. (2006). Climate Impacts of the Atlantic Multidecadal Oscillation. Geophys. Res. Lett. 33, L17706. doi:10.1029/ 2006GL026242

Kobayashi, S., Ota, Y., Harada, Y., Ebita, A., Moriya, M., Onoda, H., et al. (2015). The JRA-55 Reanalysis: General Specifications and Basic Characteristics. J. Meteorol. Soc. Jpn. 93, 5-48. doi:10.2151/jmsj.2015-001

Kosaka, Y., Nakamura, H., Watanabe, M., and Kimoto, M. (2009). Analysis on the Dynamics of a Wave-like Teleconnection Pattern along the Summertime Asian Jet Based on a Reanalysis Dataset and Climate Model Simulations. J. Meteorol. Soc. Jpn. 87 (3), 561-580. doi:10.2151/jmsj.87.561

Krishnamurti, T. N., and Bhalme, H. N. (1976). Oscillations of a Monsoon System. Part I. Observational Aspects : Observational Aspects. J. Atmos. Sci. 33, 1937-1954. doi:10.1175/1520-0469(1976)033<1937:ooamsp>2.0.co;2

Lei, X., and Yang, X. (2008). Interannual Variation Characteristic of Eastern Hemispheric Crossequatorial Flow and its Contemporaneous Relationships with Temperature and Rainfall in China. J. Trop. Meteorol. 24, 127-135. (in Chinese). doi:10.1016/s1872-2075(08)60025-4

Li, S., and Bates, G. T. (2007). Influence of the Atlantic Multidecadal Oscillation on the Winter Climate of East China. Adv. Atmos. Sci. 24, 126-135. doi:10.1007/ s00376-007-0126-6
Li, S., Perlwitz, J., Quan, X., and Hoerling, M. P. (2008). Modelling the Influence of North Atlantic Multidecadal Warmth on the Indian Summer Rainfall. Geophys. Res. Lett. 35, L05804. doi:10.1029/2007GL032901

Lin, J.-S., Wu, B., and Zhou, T.-J. (2016). Is the Interdecadal Circumglobal Teleconnection Pattern Excited by the Atlantic Multidecadal Oscillation? Atmos. Oceanic Sci. Lett. 9 (6), 451-457. doi:10.1080/16742834.2016.1233800

Lin, P., Yu, Z., Lü, J., Ding, M., Hu, A., and Liu, H. (2019). Two Regimes of Atlantic Multidecadal Oscillation: Cross-basin Dependent or Atlantic-intrinsic. Sci. Bull. 64, 198-204. doi:10.1016/j.scib.2018.12.027

Liu, B., He, J., and Wang, L. (2009). Characteristics of the South Asia High Establishment Processes above the Indo-China Peninsula from April to May and Their Possible Mechanism. Chin. J. Atmos. Sci. 33 (06), 1319-1332. doi:10.1016/S1003-6326(09)60084-4 (in Chinese).

Liu, Z. (2012). Dynamics of Interdecadal Climate Variability: A Historical Perspective*. J. Clim. 25, 1963-1995. doi:10.1175/2011jcli3980.1

Lu, R.-Y., Oh, J.-H., and Kim, B.-J. (2002). A Teleconnection Pattern in UpperLevel Meridional Wind over the North African and Eurasian Continent in Summer. Tellus A: Dyn. Meteorol. Oceanogr. 54, 44-55. doi:10.3402/ tellusa.v54i1.12122

Lu, R., Dong, B., and Ding, H. (2006). Impact of the Atlantic Multidecadal Oscillation on the Asian Summer Monsoon. Geophys. Res. Lett. 33, L24701. doi:10.1029/2006GL027655

Luo, F., Li, S., and Furevik, T. (2011). The Connection between the Atlantic Multidecadal Oscillation and the Indian Summer Monsoon in Bergen Climate Model Version 2.0. J. Geophys. Res. 116, D19117. doi:10.1029/ 2011JD015848

Mason, R. B., and Anderson, C. E. (1963). The Development and Decay of the 100Mb. Summertime Anticyclone over Southern Asia. Mon. Wea. Rev. 91 (1), 3-12. doi:10.1175/1520-0493(1963)091<0003:tdadot $>2.3 . c 0 ; 2$

Nan, S., Li, J., Yuan, X., and Zhao, P. (2009). Boreal Spring Southern Hemisphere Annular Mode, Indian Ocean Sea Surface Temperature, and East Asian Summer Monsoon. J. Geophys. Res. 114, D02103. doi:10.1029/2008JD010045

Poli, P., Hersbach, P., Tan, D. G. H., Dee, D. P., Thépaut, J. N., Simmons, A., et al. (2013). The Data Assimilation System and Initial Performance Evaluation of the ECMWF Pilot Reanalysis of the 20th-century Assimilating Surface Observations Only (ERA-20C). ERA Rep. Ser. 14, 62, 2013 . Available online at: http://www. ecmwf.int/sites/default/files/elibrary/2013/11699-dataassimilation-systemand-initial-performance-evaluation-ecmwfpilot-reanalysis-20th.pdf.

Pu, B., and Cook, K. H. (2010). Dynamics of the West African Westerly Jet. J. Clim. 23 (23), 6263-6276. doi:10.1175/2010jcli3648.1

Qian, Y., Wang, O., Dong, Y., and Gong, Y. (1987). Numerical Experiment of Somali Jet. Chin. J. Atmos. Sci. 11 (2), 176-184. (in Chinese).

Qian, Y., Zhang, Q., Yao, Y., and Zhang, X. (2002). Seasonal Variation and Heat Preference of the South Asia High. Adv. Atmos. Sci. 19 (5), 821-836. doi:10.1007/s00376-002-0047-3

Rayner, N. A., Parker, D. E., Horton, E. B., Folland, C. K., Alexander, L. V., Rowell, D. P., et al. (2003). Global Analyses of Sea Surface Temperature, Sea Ice, and Night Marine Air Temperature since the Late Nineteenth Century. J. Geophys. Res. 108 (D14), 4407. doi:10.1029/2002jd002670

Ren, S., Jiang, J., and Xu, J. (2014). Application of Upper Troposphere Circulation Revealed by the Satellite IR3 Channel to Heavy Rainfall Events Analysis in the East Side of South Asia High. Meteorol. Mon. 40 (6), 697-705. (in Chinese). doi:10.7519/j.issn.1000-0526.2014.06.006

Sato, N., and Takahashi, M. (2006). Dynamical Processes Related to the Appearance of Quasi-Stationary Waves on the Subtropical Jet in the Midsummer Northern Hemisphere. J. Clim. 19 (8), 1531-1544. doi:10.1175/ JCLI3697.1

Shi, N., Feng, G., Gu, J., and Gu, D. (2007). The Climatological Variation of Global Cross-Equatorial Flow for the Period of 1948-2004. J. Trop. Meteorol. 23 (4), 326-332. (in Chinese). doi:10.3969/j.issn.1004-4965.2007.04.002

Shi, W., Xiao, Z., and Sun, H. (2017). The Correlation of Somali Jet Strength with South Asia High on Interdecadal Timescale. Chin. J. Atmos. Sci. 41 (3), 561-577. (in Chinese). doi:10.3878/j.issn.1006-9895.1609.16163

Simpson, G. C. (1921). The South-West Monsoon. Q.J.R. Meteorol. Soc. 47 (199), 151-171. doi:10.1002/qj.49704719901

Su, H., and Neelin, J. D. (2003). The Scatter in Tropical Average Precipitation Anomalies*. J. Clim. 16, 3966-3977. doi:10.1175/1520-0442(2003)016<3966: tsitap $>2.0 . \operatorname{co} ; 2$ 
Su, H., Neelin, J. D., and Meyerson, J. E. (2003). Sensitivity of Tropical Tropospheric Temperature to Sea Surface Temperature Forcing*. J. Clim. 16, 1283-1301. doi:10.1175/1520-0442-16.9.1283

Sutton, R. T., and Hodson, D. L. R. (2005). Atlantic Ocean Forcing of North American and European Summer Climate. Science 309, 115-118. doi:10.1126/ science.1109496

Sutton, R. T., and Hodson, D. L. R. (2007). Climate Response to Basin-Scale Warming and Cooling of the North Atlantic Ocean. J. Clim. 20, 891-907. doi:10.1175/JCLI403810.1175/jcli4038.1

Takaya, K., and Nakamura, H. (2001). A Formulation of a Phase-independent Wave-Activity Flux for Stationary and Migratory Quasigeostrophic Eddies on a Zonally Varying Basic Flow. J. Atmos. Sci. 58, 608-627. doi:10.1175/15200469(2001)058<0608:afoapi >2.0.co;2

Ting, M., Kushnir, Y., Seager, R., and Li, C. (2009). Forced and Internal TwentiethCentury SST Trends in the North Atlantic*. J. Clim. 22, 1469-1481. doi:10.1175/ 2008jcli2561.1

Wang, H., and Li, D. (2019). The Impacts of Global Sea Surface Temperature on Decadal Transitions of Summer Precipitation over Eastern China at Global Warming Transition Points. J. Trop. Meteorol. 35 (3), 398-408. doi:10.16032/ j.issn.1004-4965.2019.037 (in Chinese).

Wang, Y., Li, S., and Luo, D. (2009). Seasonal Response of Asian Monsoonal Climate to the Atlantic Multidecadal Oscillation. J. Geophys. Res. 114, D02112. doi:10.1029/2008JD010929

Wang, L., Xu, P., Chen, W., and Liu, Y. (2017). Interdecadal Variations of the Silk Road Pattern. J. Clim. 30 (24), 9915-9932. doi:10.1175/jcli-d-17-0340.1

Watanabe, T., and Yamazaki, K. (2014). The Upper-Level Circulation Anomaly over Central Asia and its Relationship to the Asian Monsoon and Mid-latitude Wave Train in Early Summer. Clim. Dyn. 42, 2477-2489. doi:10.1007/s00382013-1888-4

Wei, W., Zhang, R., Wen, M., Rong, X., and Li, T. (2014). Impact of Indian Summer Monsoon on the South Asian High and its Influence on Summer Rainfall over China. Clim. Dyn. 43, 1257-1269. doi:10.1007/s00382-013-1938-y

Wei, W., Zhang, R., Wen, M., Kim, B.-J., and Nam, J.-C. (2015). Interannual Variation of the South Asian High and its Relation with Indian and East Asian Summer Monsoon Rainfall. J. Clim. 28, 2623-2634. doi:10.1175/jcli-d-14-00454.1

Wu, B., Zhou, T., and Li, T. (2016). Impacts of the Pacific-Japan and Circumglobal Teleconnection Patterns on the Interdecadal Variability of the East Asian Summer Monsoon. J. Clim. 29, 3253-3271. doi:10.1175/jcli-d-15-0105.1

Xiao, Z., Shi, W., and Yang, P. (2015). Possible Causes of the Interdecadal Transition of the Somali Jet Around the Late 1990s. J. Meteorol. Res. 29 (2), 214-227. doi:10.1007/s13351-015-4103-1

Xie, S.-P., Hu, K., Hafner, J., Tokinaga, H., Du, Y., Huang, G., et al. (2009). Indian Ocean Capacitor Effect on Indo-Western Pacific Climate during the Summer Following El Niño. J. Clim. 22, 730-747. doi:10.1175/ 2008 jcli2544.1

Xu, H., He, J., and Dong, M. (2001). Interannual Variability of the Meiyu Onset and its Association with North Atlantic Oscillation and SSTA over North Atlatic. ACTA Meteorol. Sin. 59 (6), 694-706. doi:10.11676/qxxb2001.073 (in Chinese).
Yang, G., Li, C., and Tan, Y. (2013). A Study on Interdecadal Variation of South Asian High and its Possible Cause (In Chinese). J. Trop. Meteorol. 29 (4), 529-539. doi:10.3969/j.issn.1004-4965.2013.04.001

Yasui, S., and Watanabe, M. (2010). Forcing Processes of the Summertime Circumglobal Teleconnection Pattern in a Dry AGCM. J. Clim. 23 (8), 2093-2114. doi:10.1175/2009JCLI3323.1

Zhang, R., and Delworth, T. L. (2006). Impact of Atlantic Multidecadal Oscillations on India/Sahel Rainfall and Atlantic Hurricanes. Geophys. Res. Lett. 33, L17712. doi:10.1029/2006GL026267

Zhang, Q., Qian, Y., and Zhang, X. (2000). Interannual and Interdecadal Variations of the South Asia High. Chin. J. Atmos. Sci. 24 (1), 67-78. (in Chinese). doi:10.3878/j.issn.1006-9895.2000.01.07

Zhang, Q., Wu, G., and Qian, Y. (2002). The Bimodality of the $100 \mathrm{hPa}$ South Asia High and its Relationship to the Climate Anomaly over East Asia in Summer. J. Meteorol. Soc. Jpn. 80, 733-744. doi:10.2151/jmsj.80.733

Zhang, P., Yang, S., and Kousky, V. E. (2005). South Asian High and Asian-PacificAmerican Climate Teleconnection. Adv. Atmos. Sci. 22, 915-923. doi:10.1007/ bf02918690

Zhou, Y., and Zheng, D. (1999). Monte Carlo Simulation Tests of Correlation Significance Levels. Acta Geod. et Cartographica Sin. 28 (4), 313-318. (in Chinese).

Zhou, N., Yu, Y., and Qian, Y. (2006). Simulations of the 100-hPa South Asian High and Precipitation over East Asia with IPCC Coupled GCMs. Adv. Atmos. Sci. 23 (3), 375-390. doi:10.1007/s00376-006-0375-9

Zhu, Y. (2012). Variations of the Summer Somali and Australia Cross-Equatorial Flows and the Implications for the Asian Summer Monsoon. Adv. Atmos. Sci. 29 (3), 509-518. doi:10.1007/s00376-011-1120-6

Conflict of Interest: WS and QW were employed by the company CSSC Marine Technology Co. Ltd.

The remaining authors declare that the research was conducted in the absence of any commercial or financial relationships that could be construed as a potential conflict of interest.

Publisher's Note: All claims expressed in this article are solely those of the authors and do not necessarily represent those of their affiliated organizations, or those of the publisher, the editors, and the reviewers. Any product that may be evaluated in this article, or claim that may be made by its manufacturer, is not guaranteed or endorsed by the publisher.

Copyright (c) 2021 Shi, Wang, Xiao, Cheng and Duan. This is an open-access article distributed under the terms of the Creative Commons Attribution License (CC BY). The use, distribution or reproduction in other forums is permitted, provided the original author(s) and the copyright owner(s) are credited and that the original publication in this journal is cited, in accordance with accepted academic practice. No use, distribution or reproduction is permitted which does not comply with these terms. 